\title{
Dual Photoredox/Gold Catalysis Arylative Cyclization of ortho-alkynylphenols with Aryl Diazonium Salts: A Flexible Synthesis of Benzofurans
}

Zhonghua Xia, Omar Khaled, Virginie Mouriès-Mansuy, Cyril Ollivier* and Louis Fensterbank*

\section{Sorbonne Universités - UPMC Univ Paris 06}

UMR CNRS 8232, Institut Parisien de Chimie Moléculaire, 4 place Jussieu, C.229, F-75005 Paris, France Fax: (+33) 1-4427-7360; cyril.ollivier@upmc.fr, louis.fensterbank@upmc.fr

\section{Table of Contents}

${ }^{1} \mathrm{H},{ }^{13} \mathrm{C}$ and ${ }^{19} \mathrm{~F}$ NMR Spectra and GC/MS of products. S3 
${ }^{1} \mathrm{H},{ }^{13} \mathrm{C}$ NMR and ${ }^{19} \mathrm{~F}$ Spectra of products

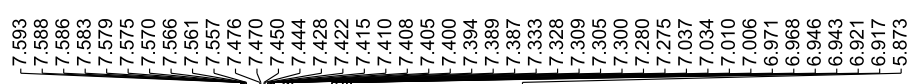
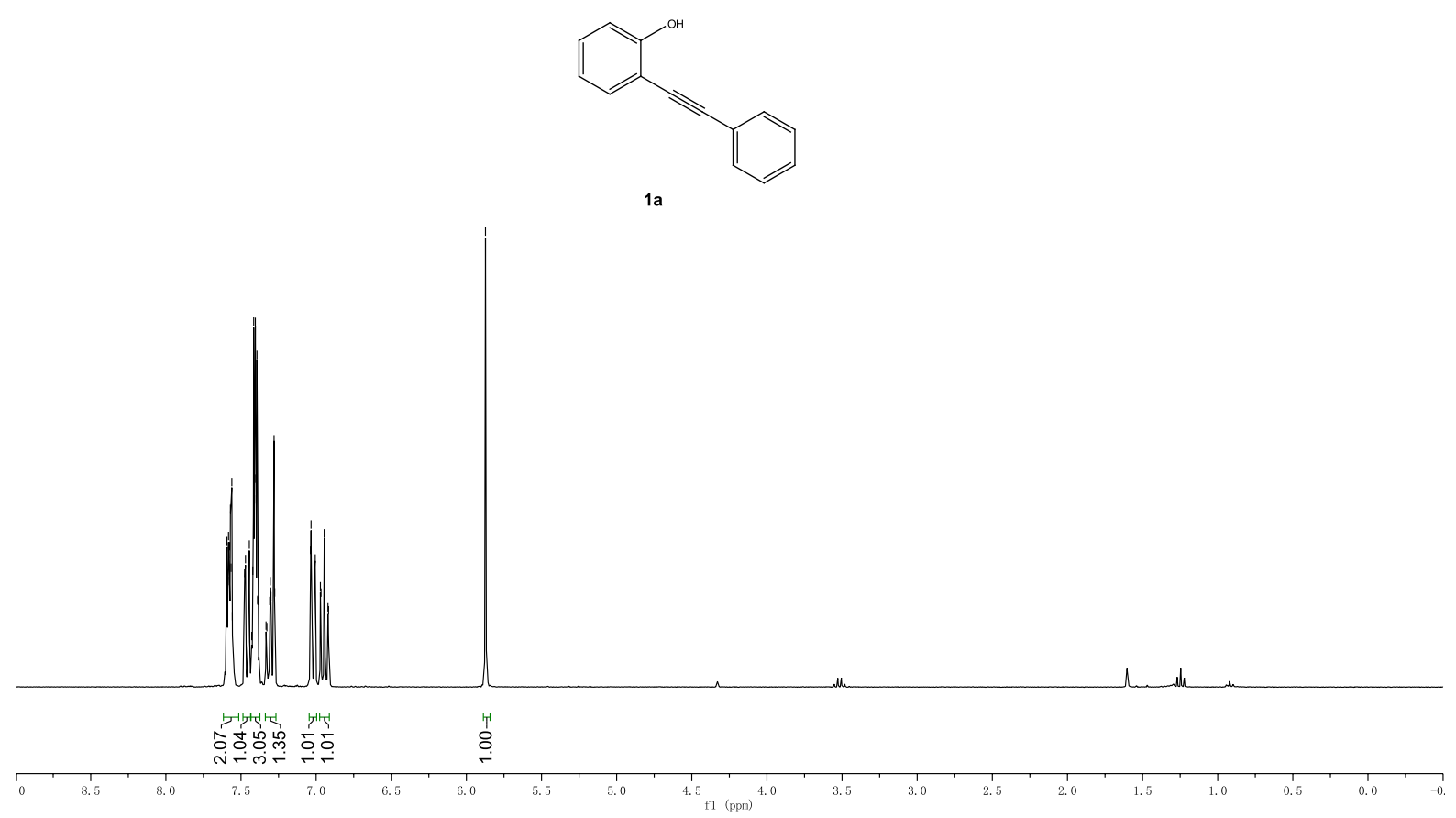

SI 


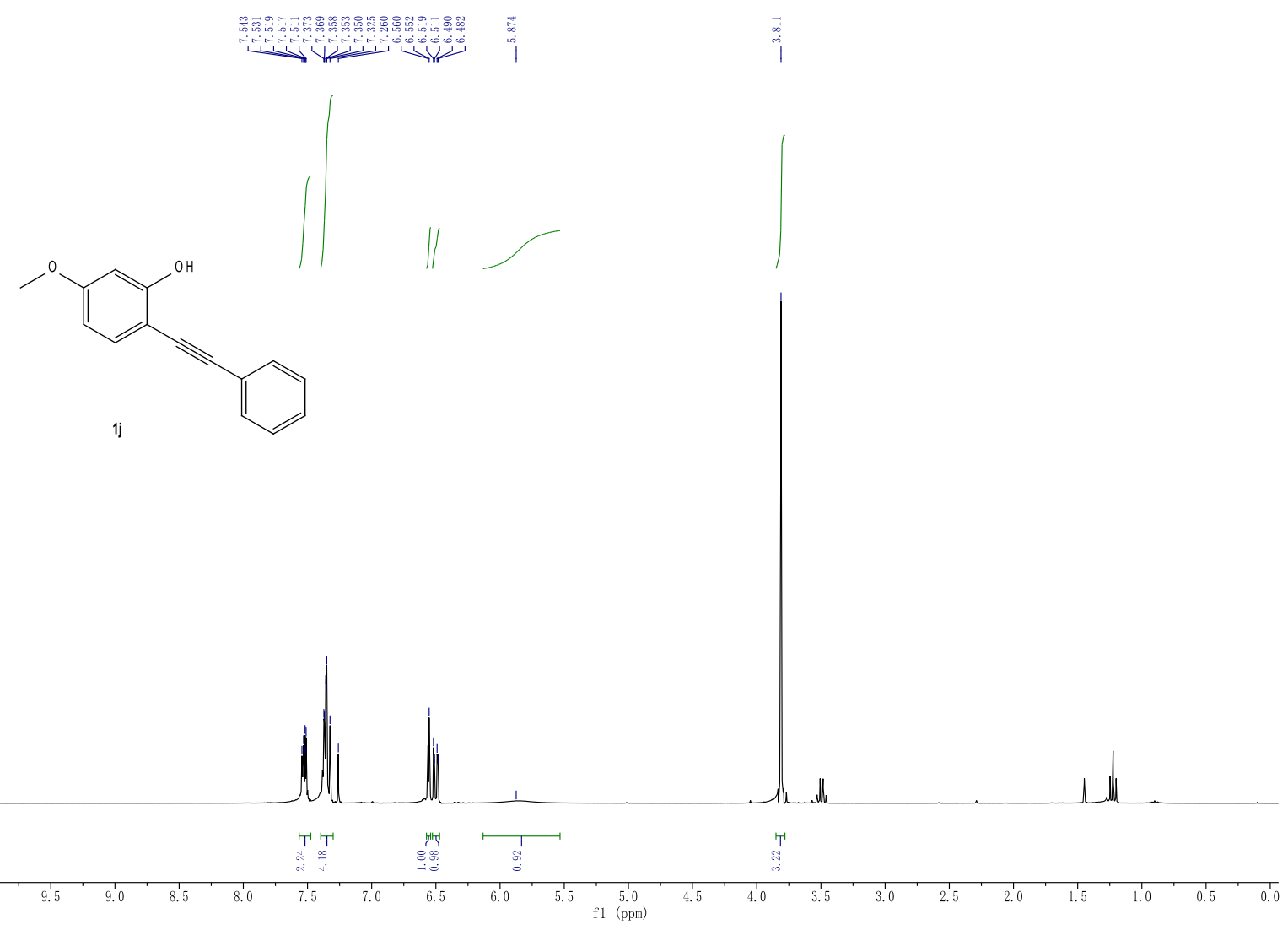

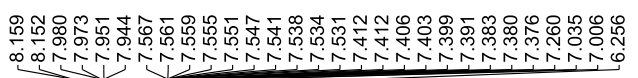

$\stackrel{8}{\circ}$
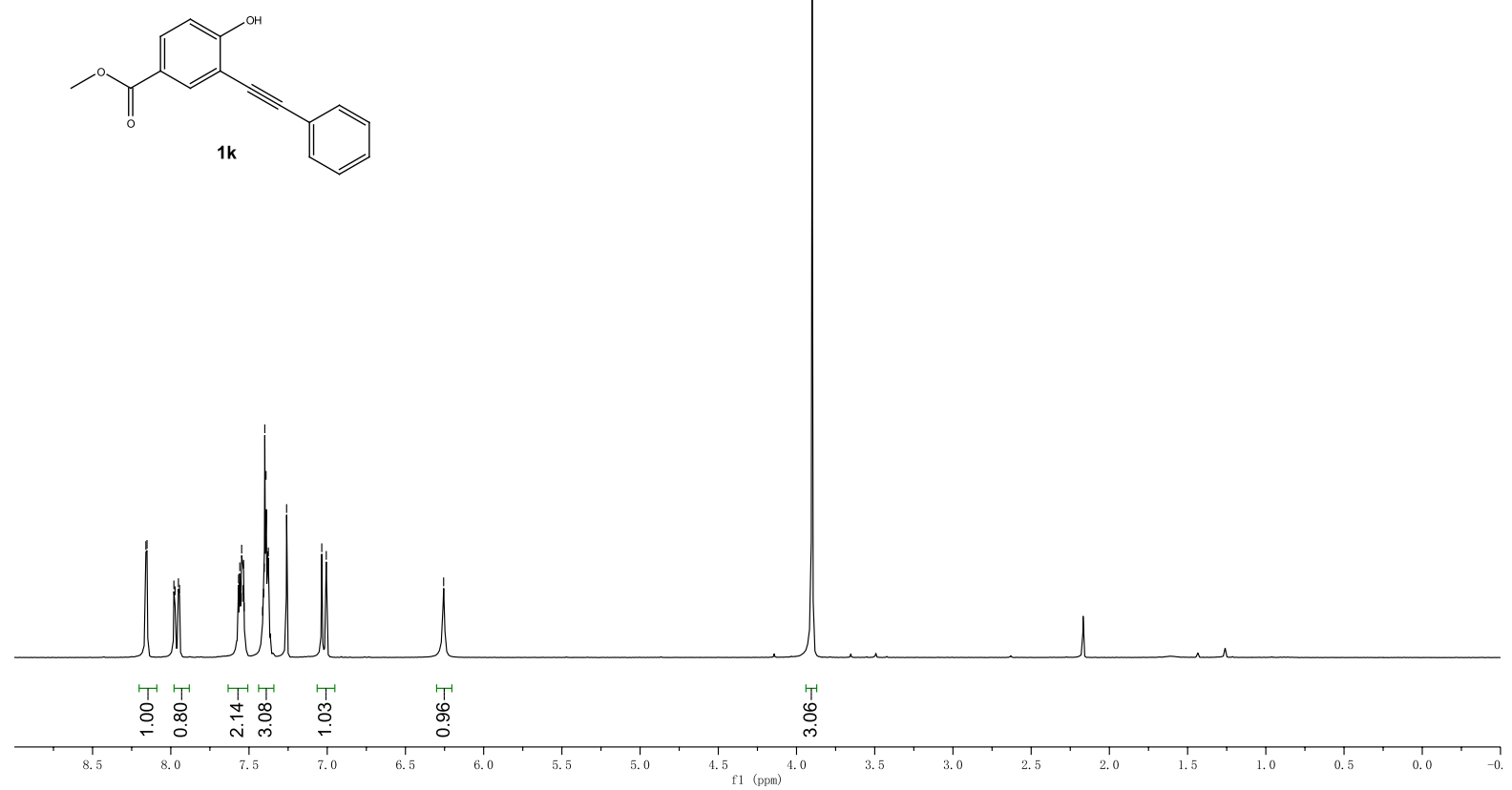

S3 

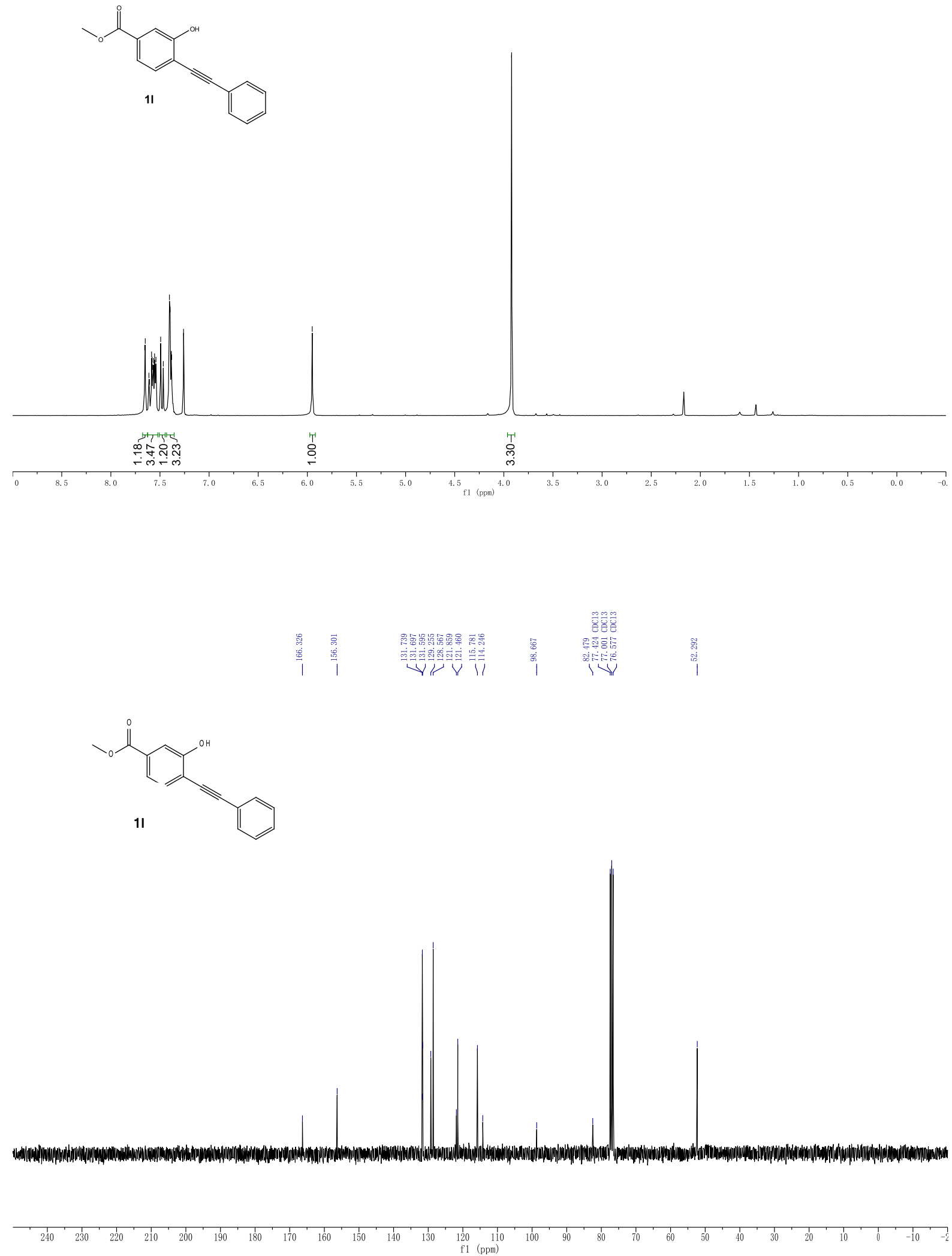

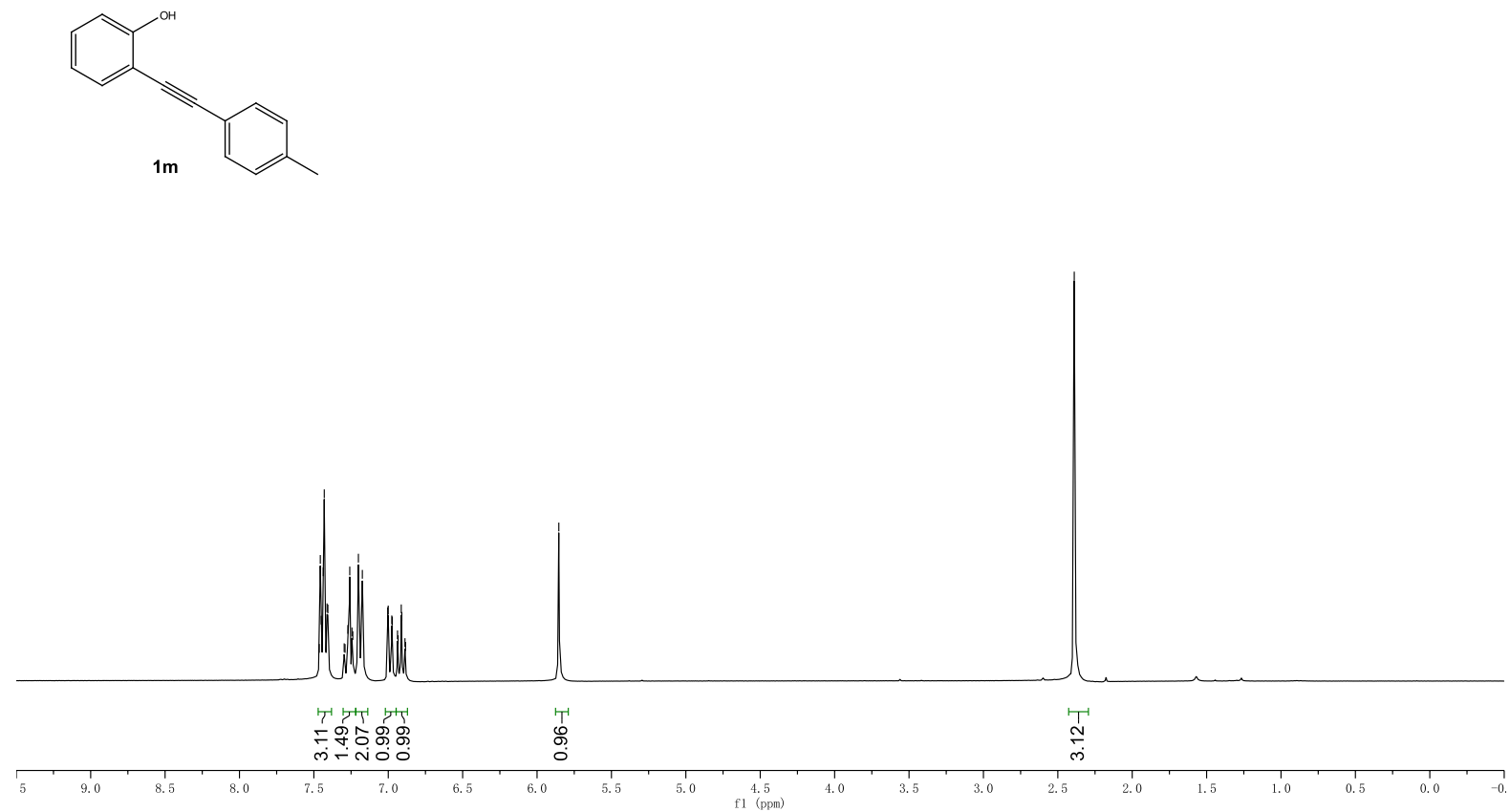

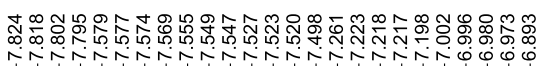

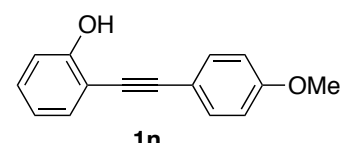

1n

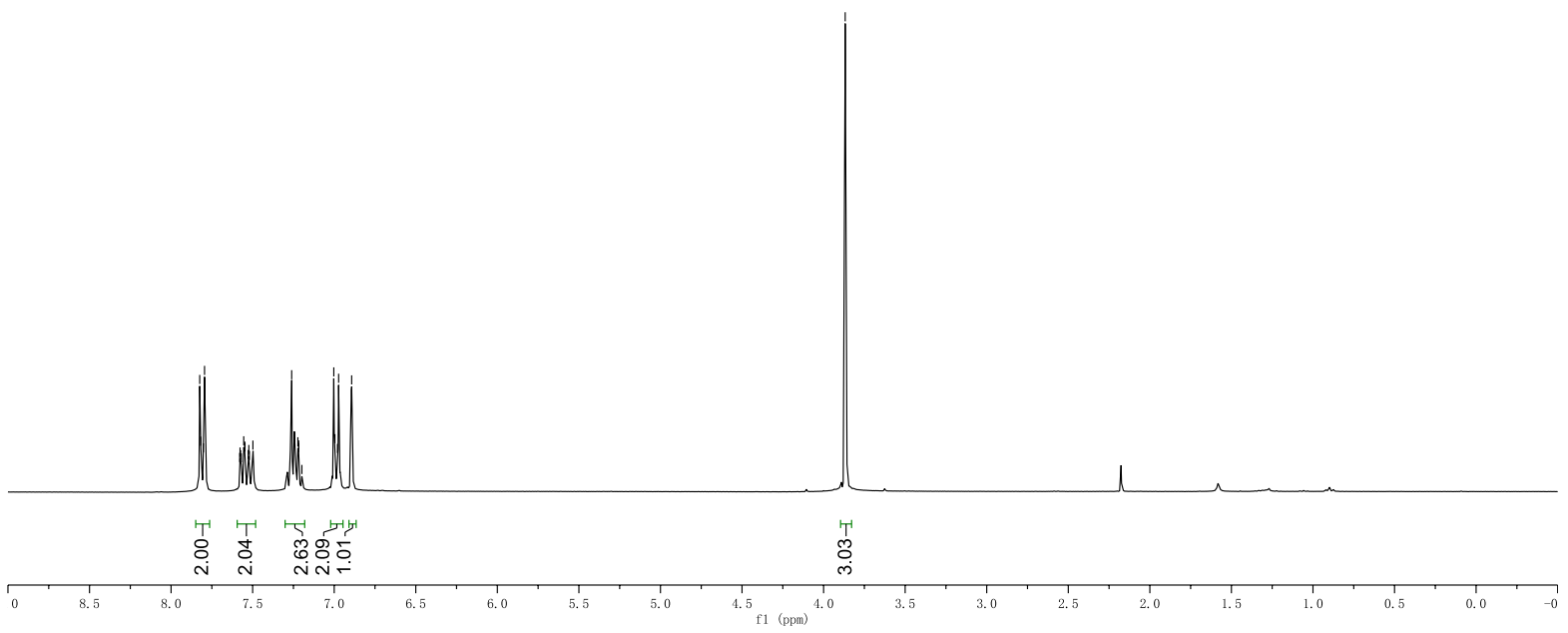




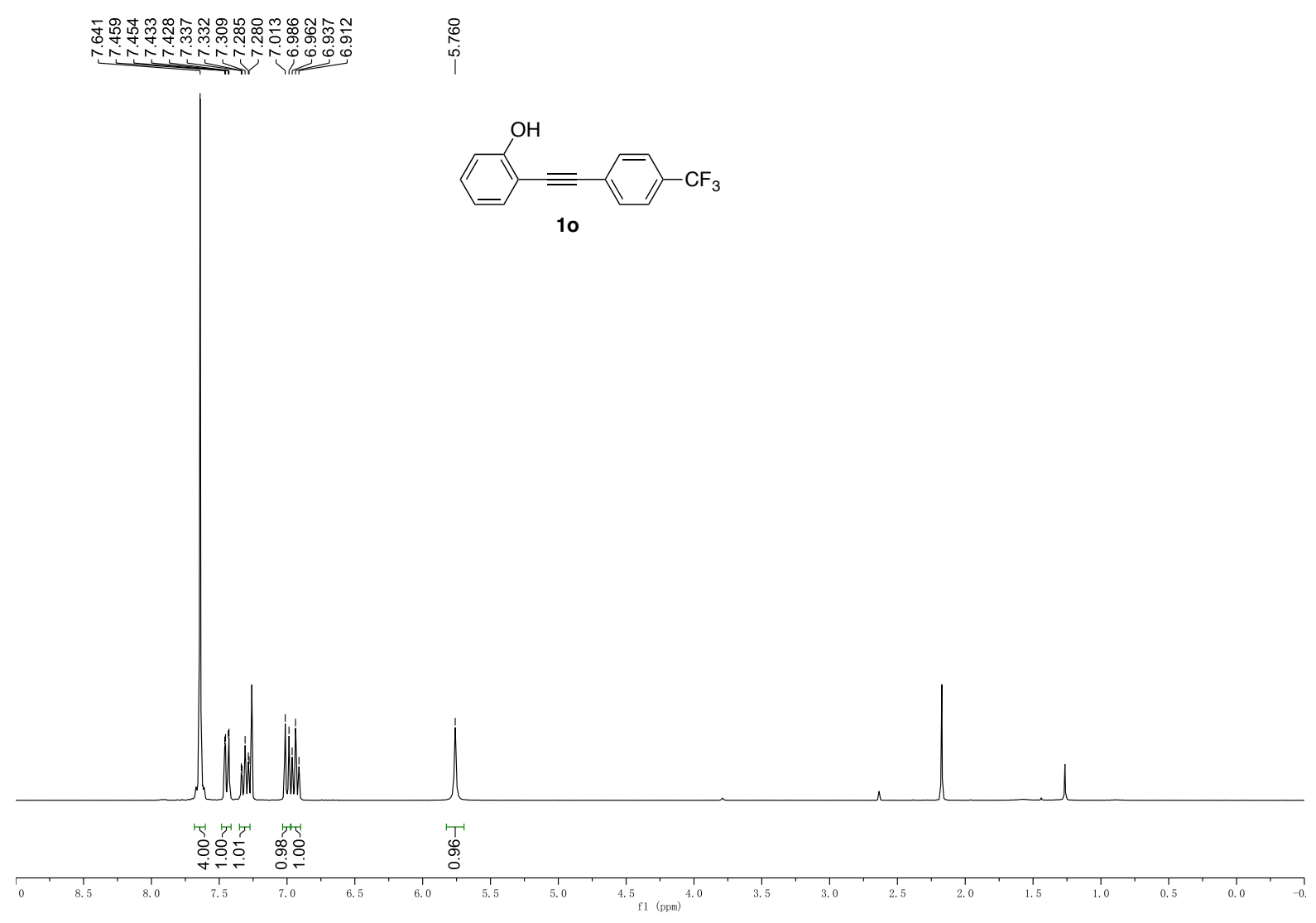

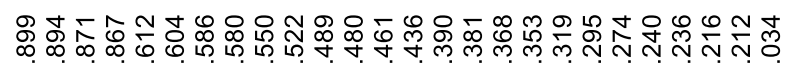

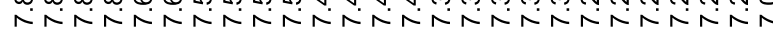

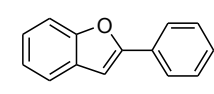

$3 a$

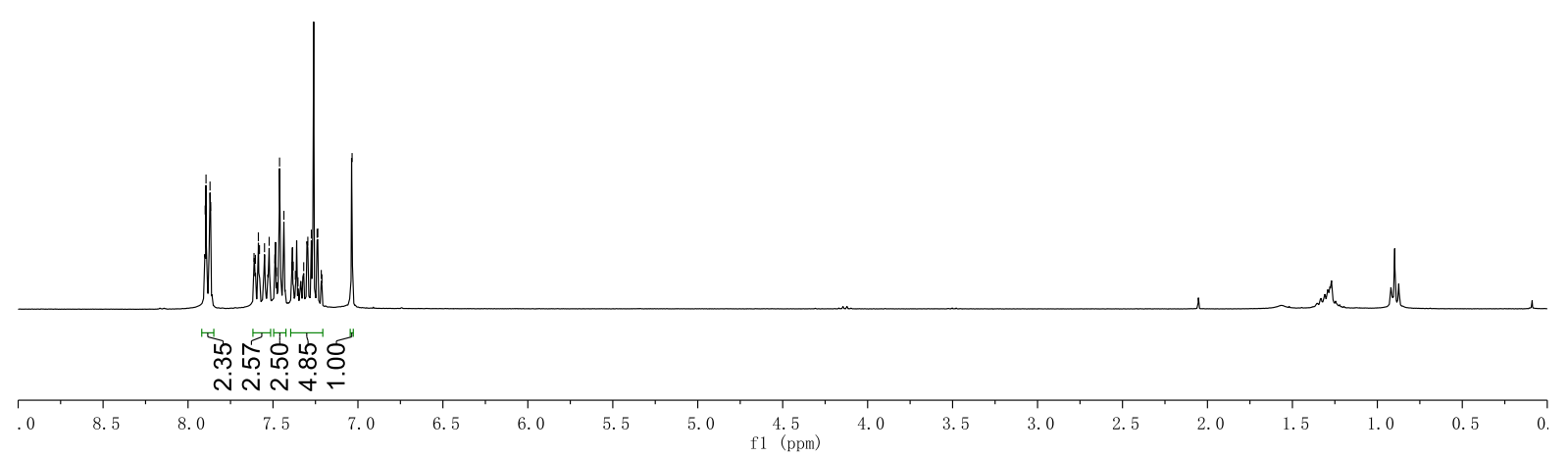



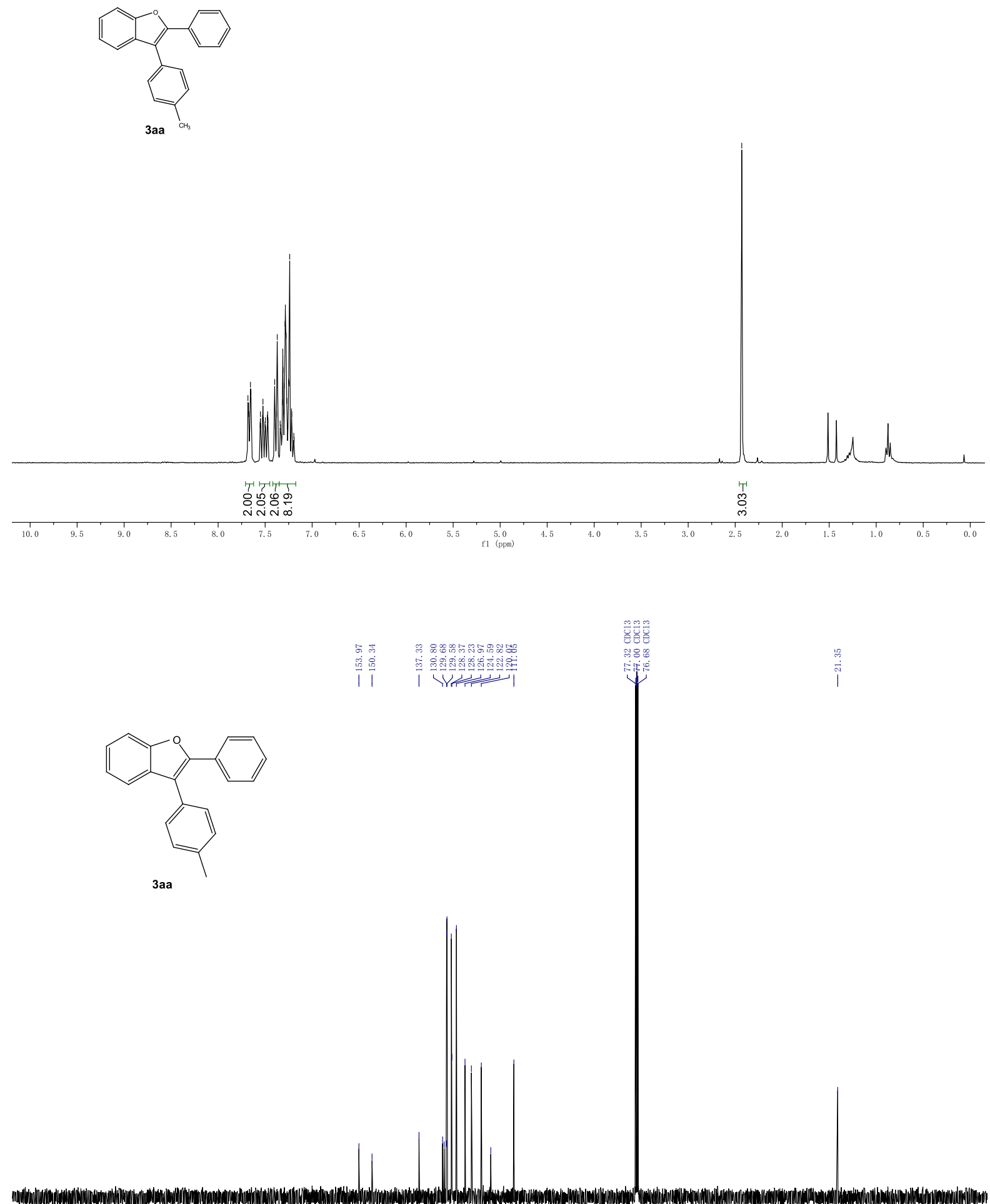

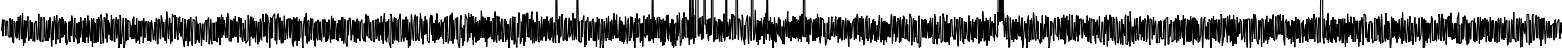

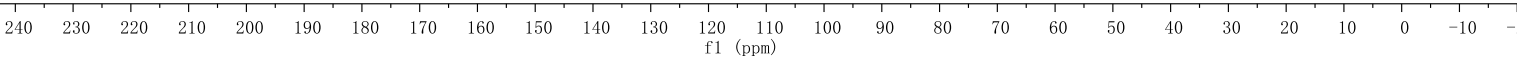




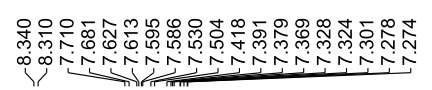
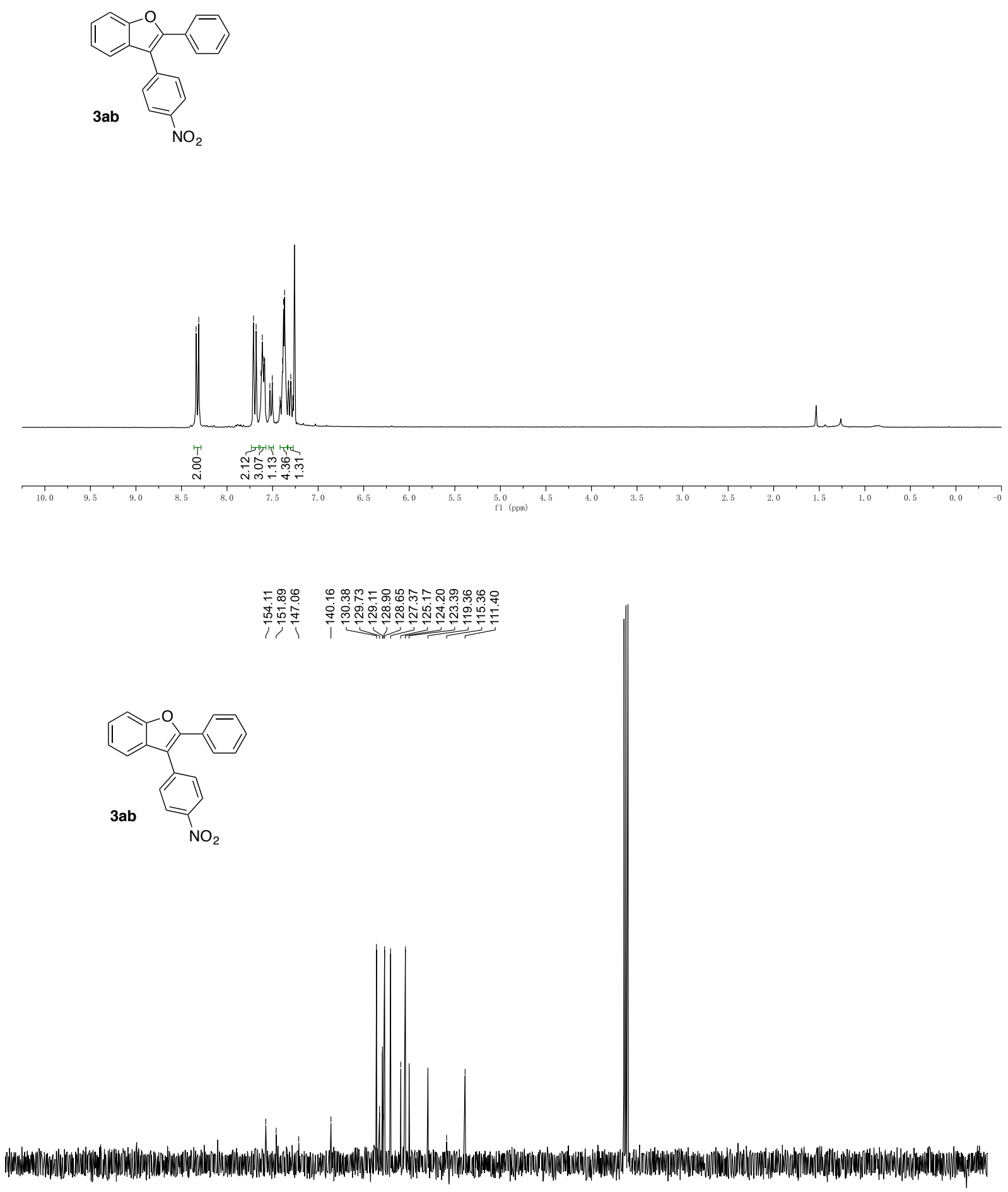

S8 


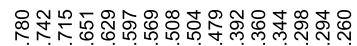

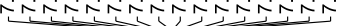

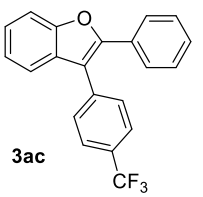

whin

ชูำ
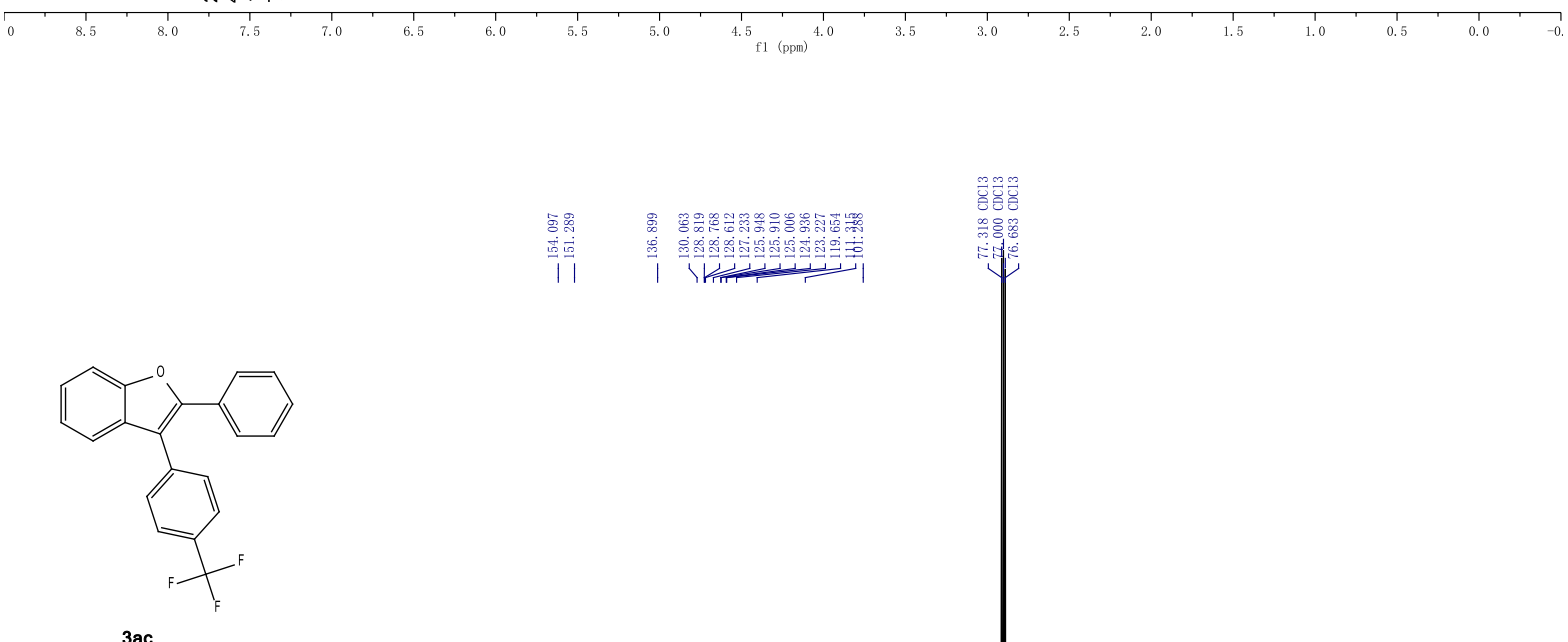

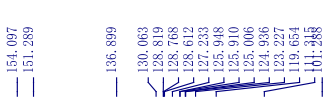

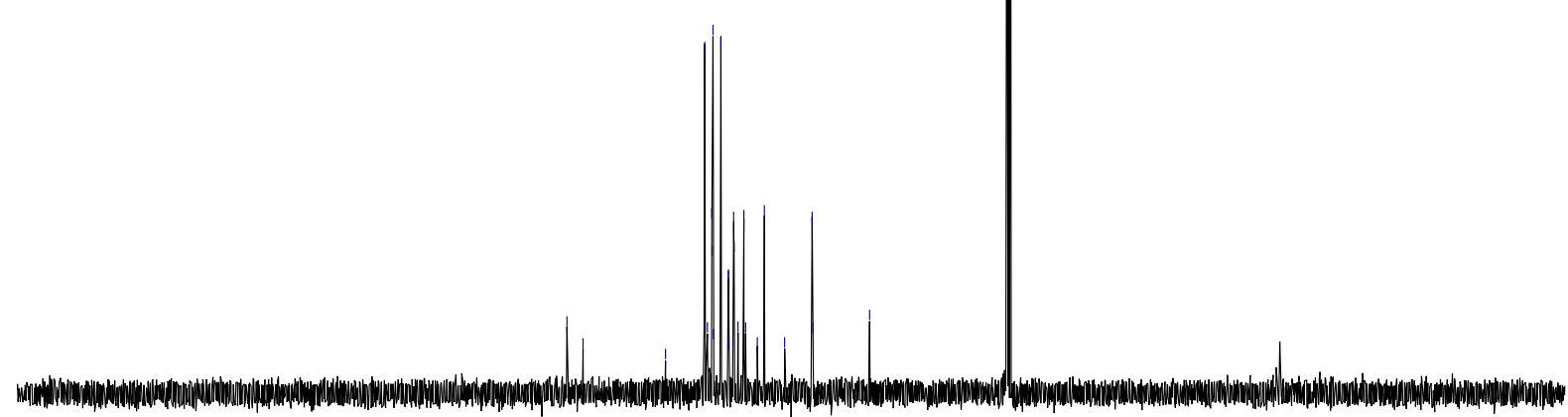

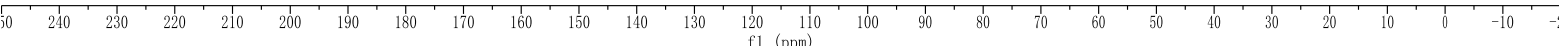




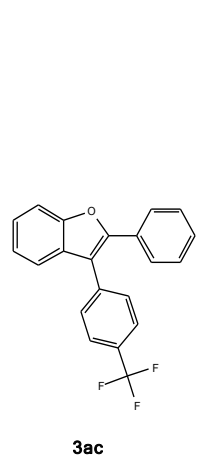

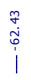

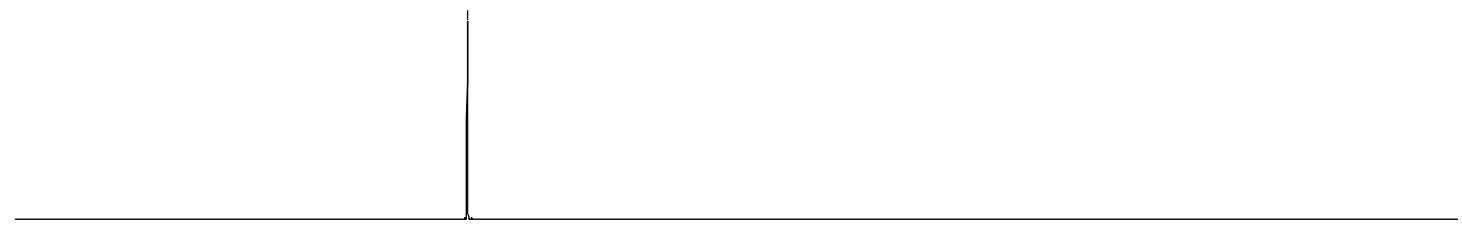

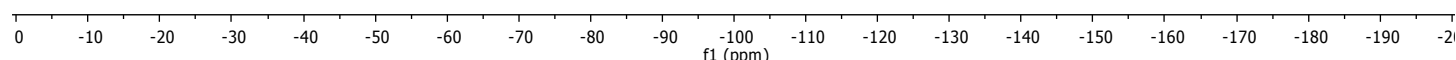




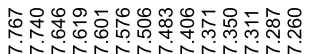
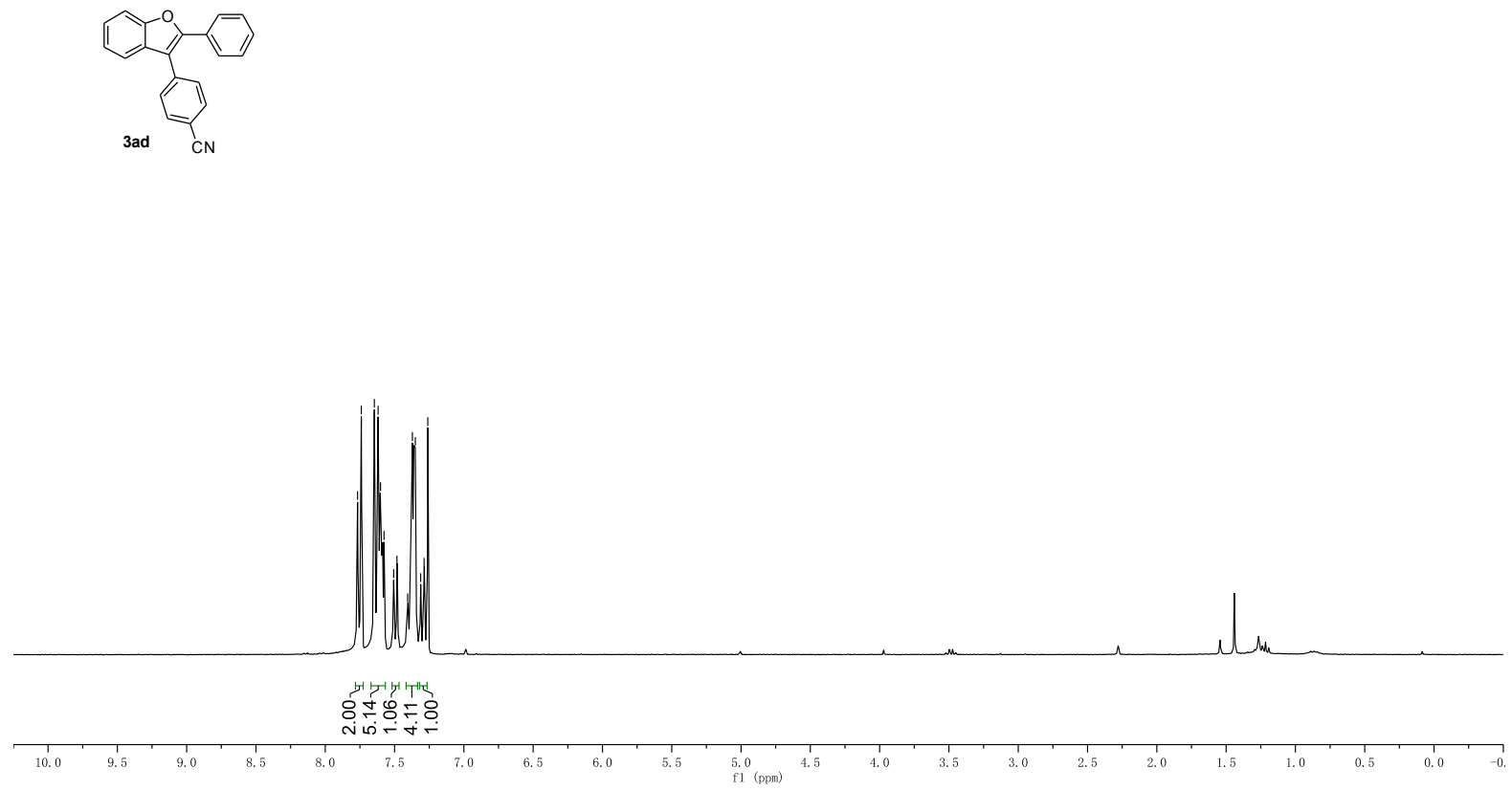

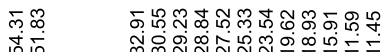

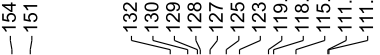
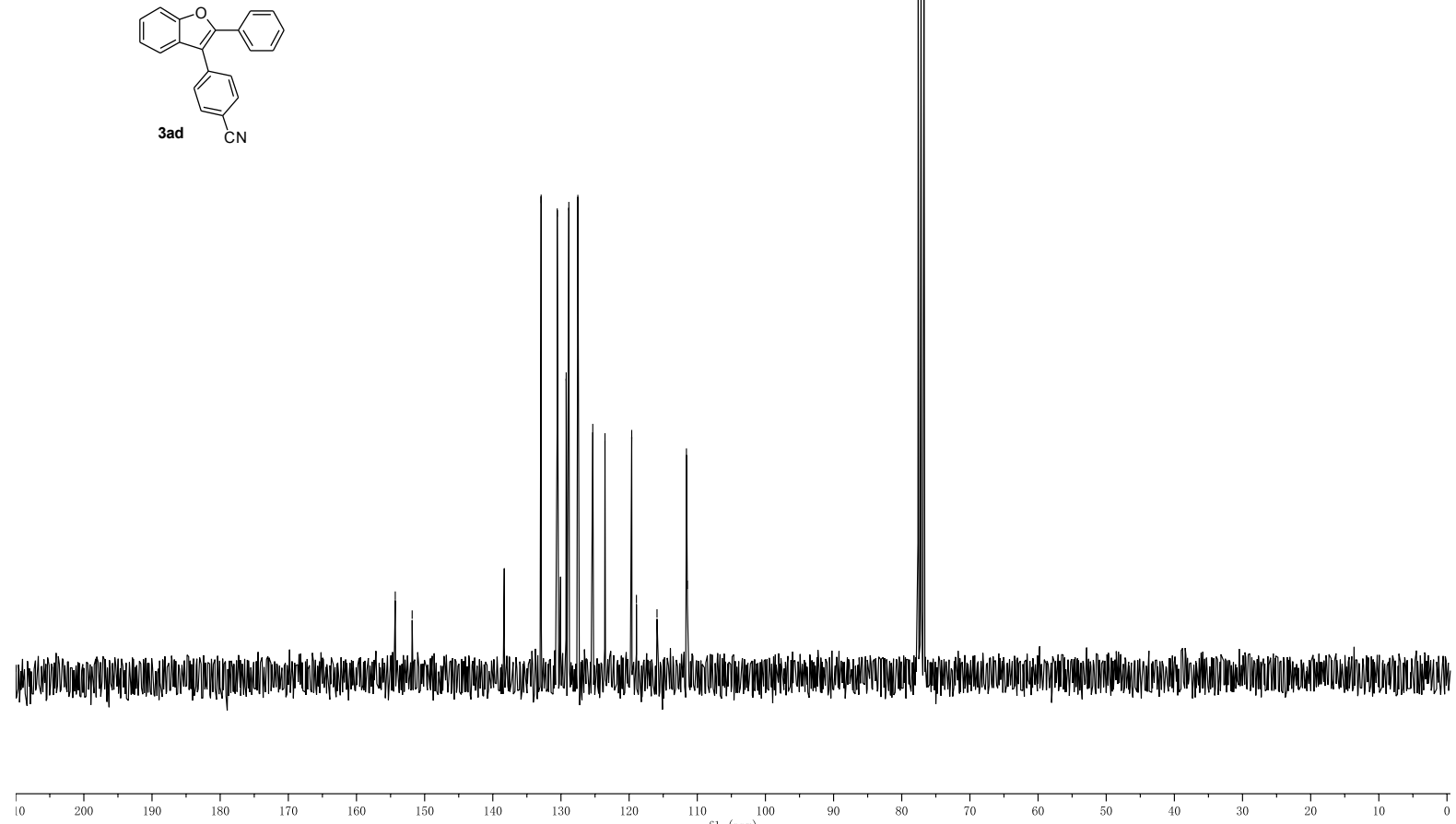

150

${ }_{130}^{1} \mathbb{1 2 0}_{110}^{1} \underset{\mathrm{f} 1(\mathrm{pmm})}{100}$ 


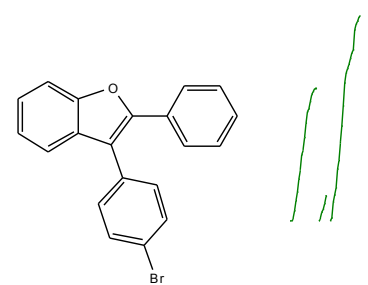

3ae

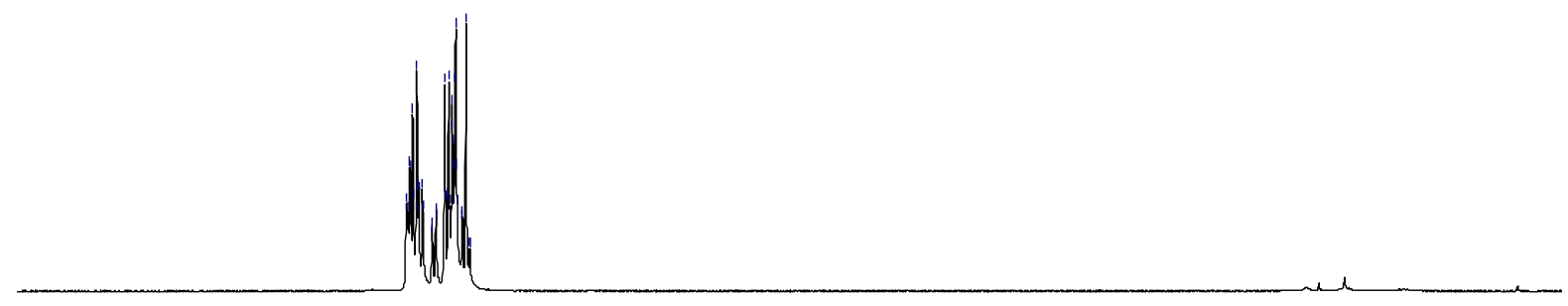

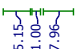

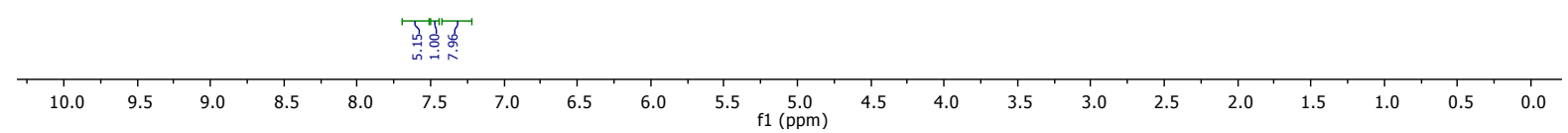

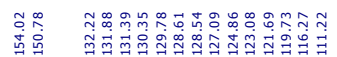

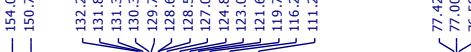

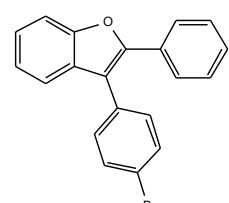

3ae

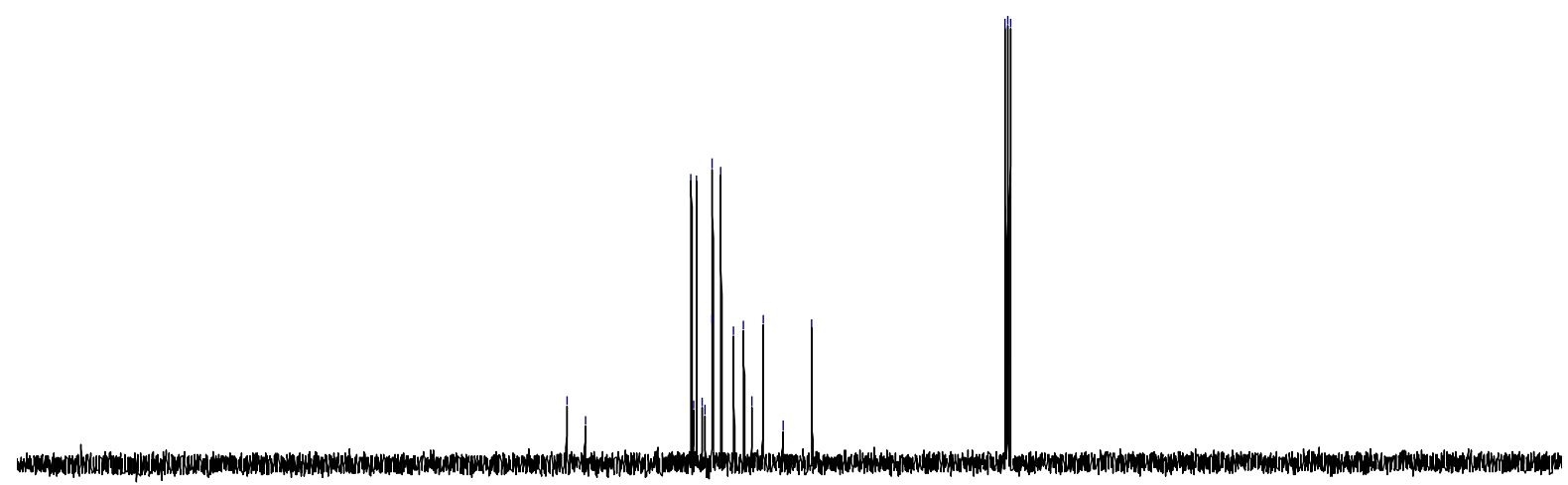

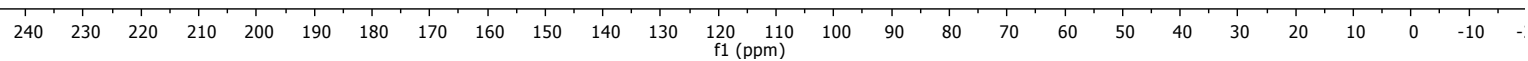


Qualitative Analysis Report

Data Filename

Sample Type

Instrument Name

Acq Method

IRM Calibration Status

Comment

Expected Barcode

Dual Inj Vol

TunePath

Acquisition Time \#2 2016-04-20 12:49:55Z

RunCompletedFlag True

\section{A_16110_3C.D}

paris_E__CH2Cl2.M

Not Applicable
Sample Name 3e

Position 11

User Name

Acquired Time 4/20/2016 2:49:55 PM

DA Method default.m

\begin{tabular}{lll}
\multicolumn{1}{c}{$\begin{array}{l}\text { Sample Amount } \\
\text { TuneName }\end{array}$} & etune20150908.u \\
D:MassHunter $\mid G C M S \backslash 1 \backslash 5977$ & MSFirmwareVersion & 6.00 .21
\end{tabular}

OperatorName

Acquisition SW MassHunter GC/MS

Version Acquisition B.07.01.1805 12-

Mar-2014 Copyright (C) 1989-

2014 Agilent Technologies,

Inc.

User Chromatograms

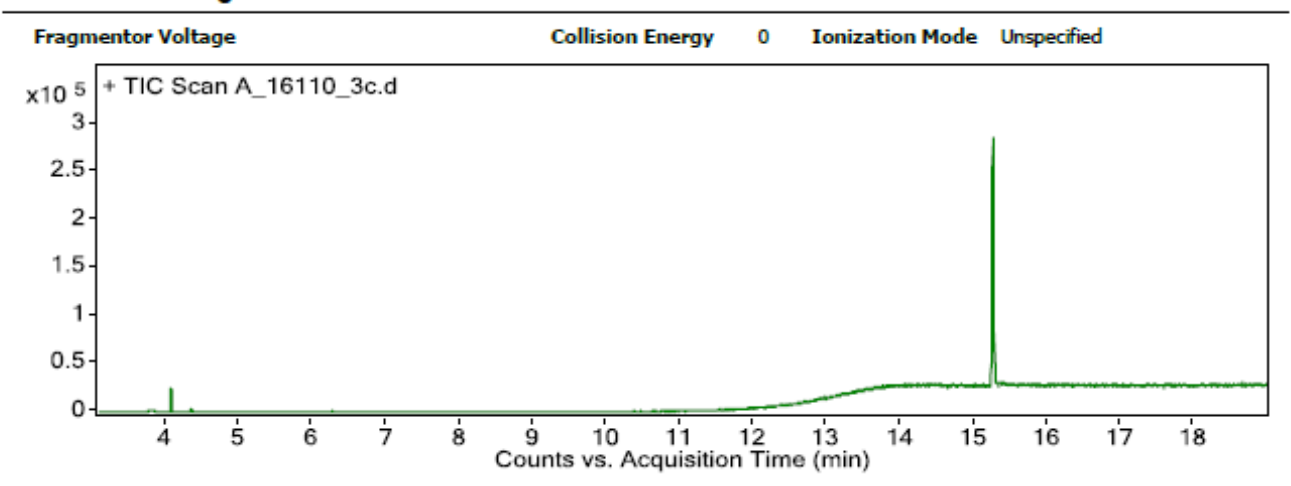

User Spectra

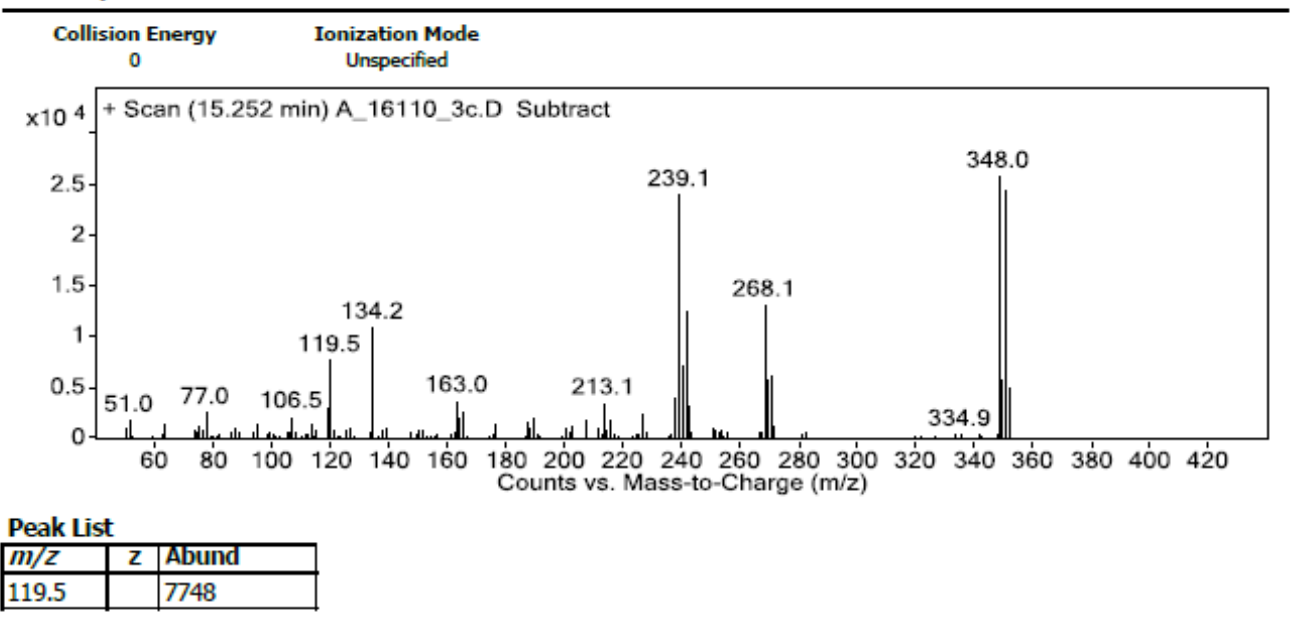


Qualitative Analysis Report

\begin{tabular}{|l|l|l|}
\hline 134.2 & & 10997 \\
\hline 239.1 & 1 & 24056 \\
\hline 240.1 & 1 & 7091 \\
\hline 241.1 & 1 & 12491 \\
\hline 268.1 & & 13201 \\
\hline 270.1 & 1 & 6173 \\
\hline 348 & 1 & 25880 \\
\hline 349 & 1 & 5843 \\
\hline 350.1 & 1 & 24472 \\
\hline
\end{tabular}

-- End Of Report -- 


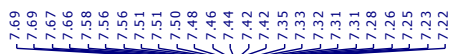

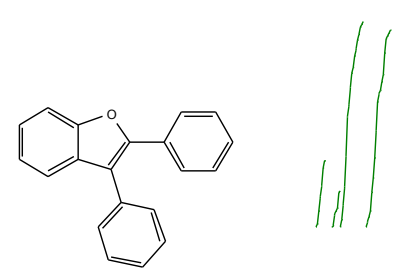

3 af

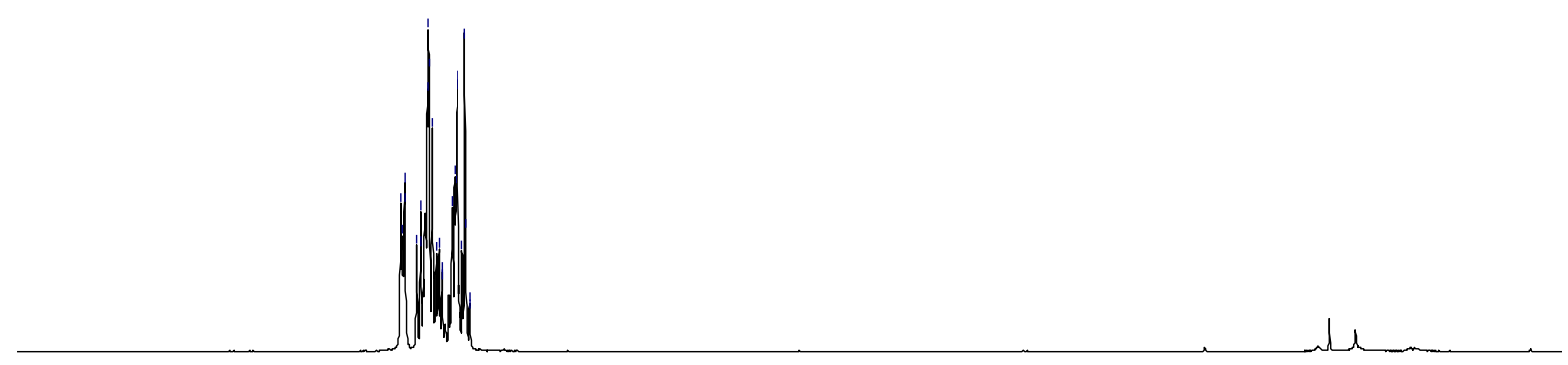

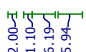
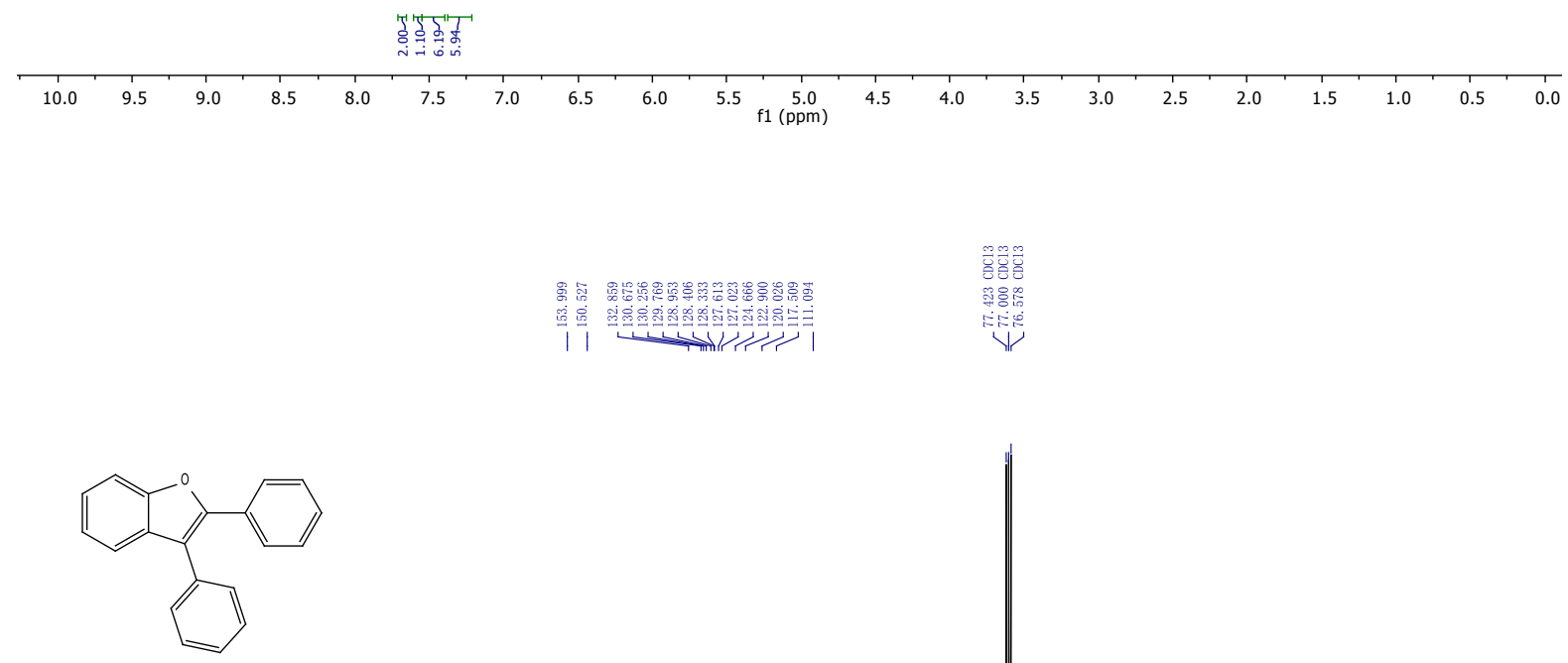

3af
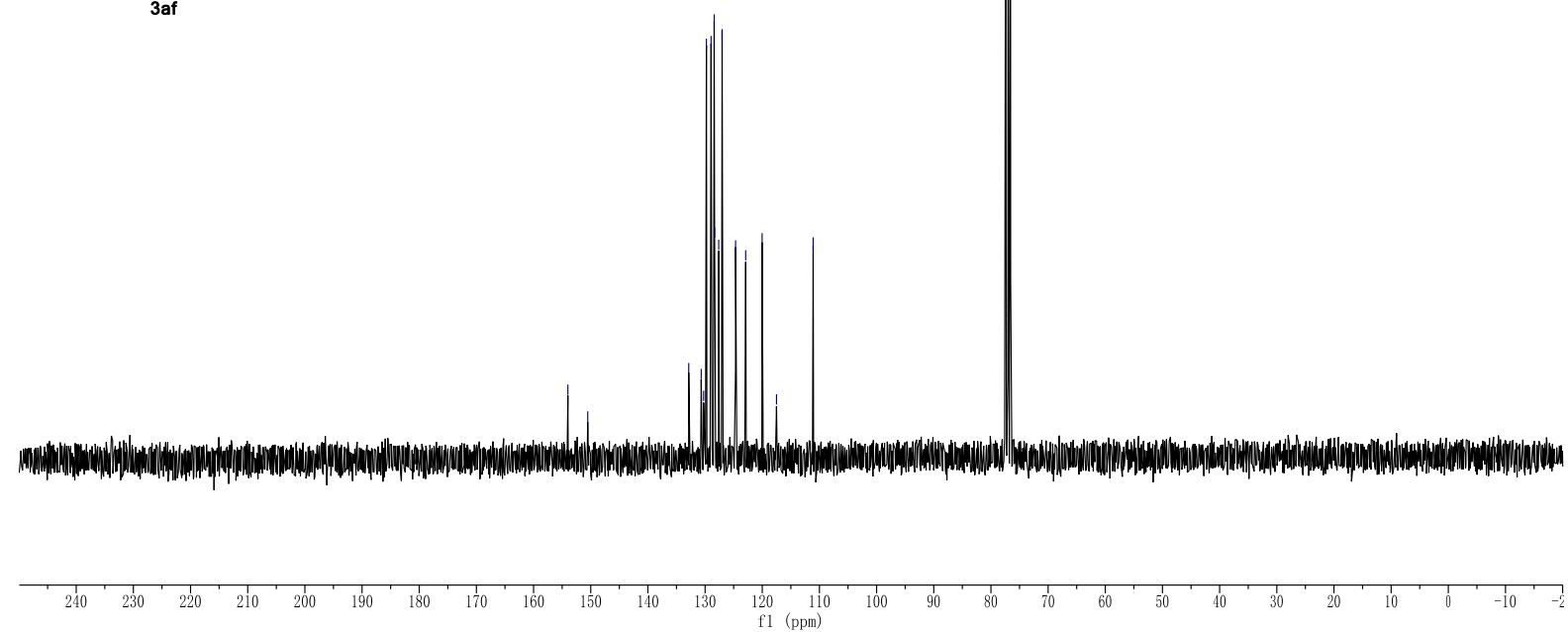


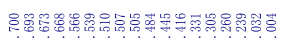

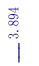

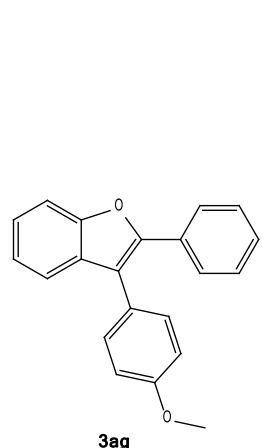

$3 a g$

$|1| \mid$
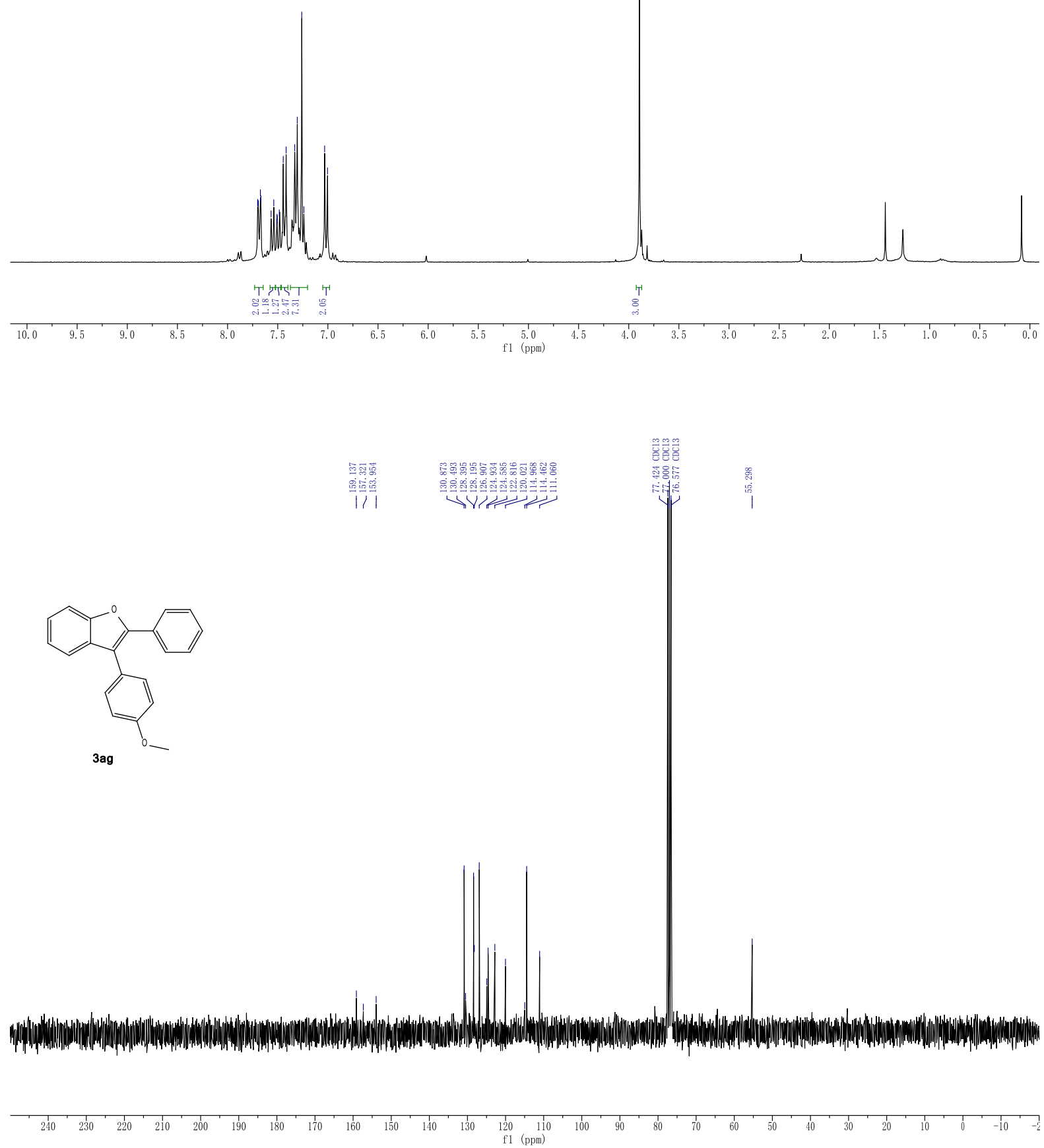

S16 


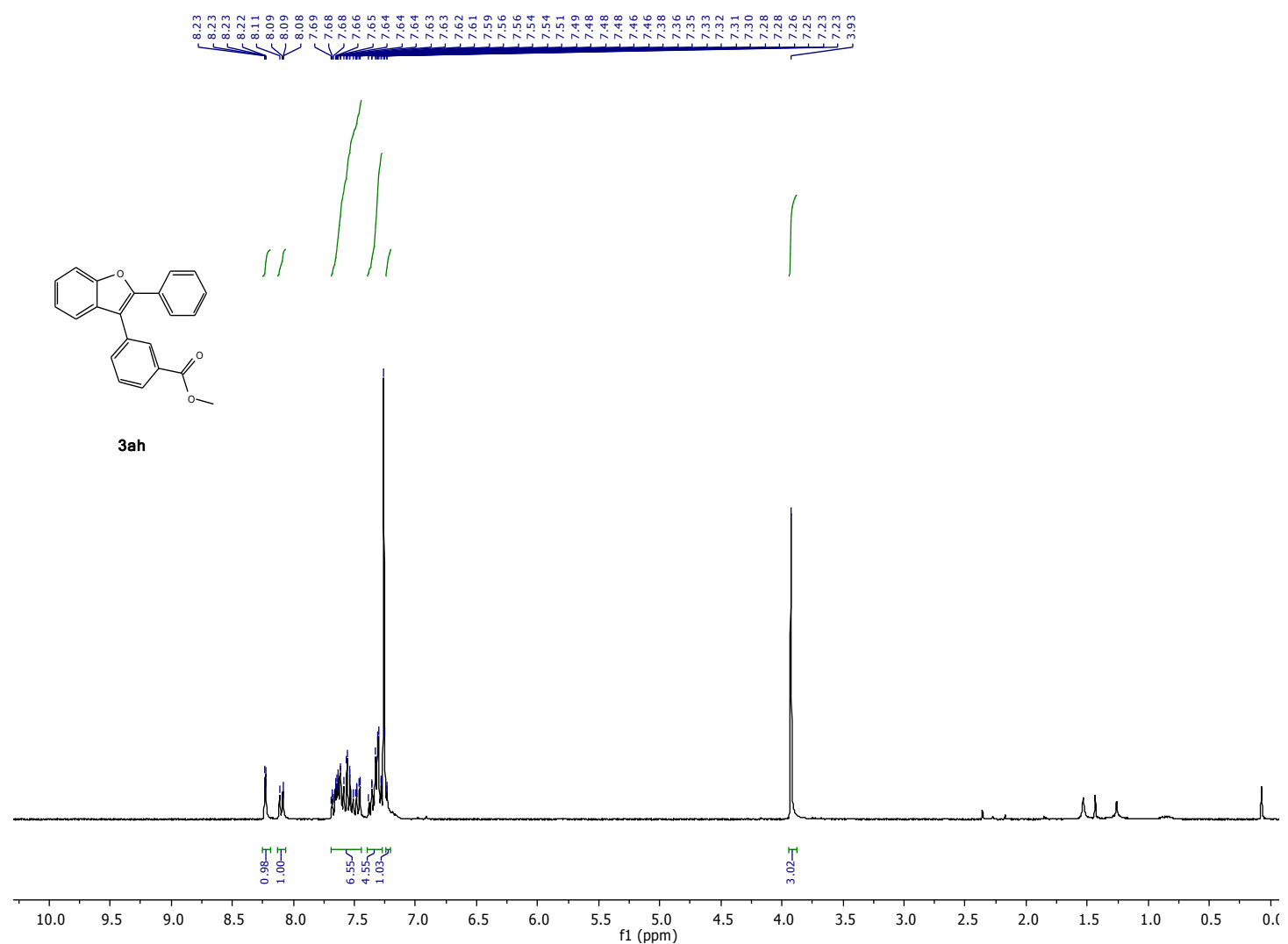

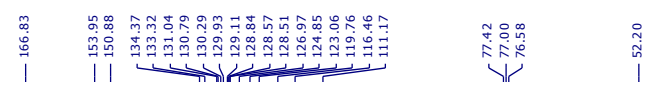

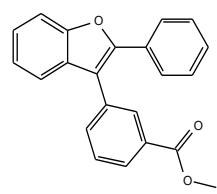

3ah

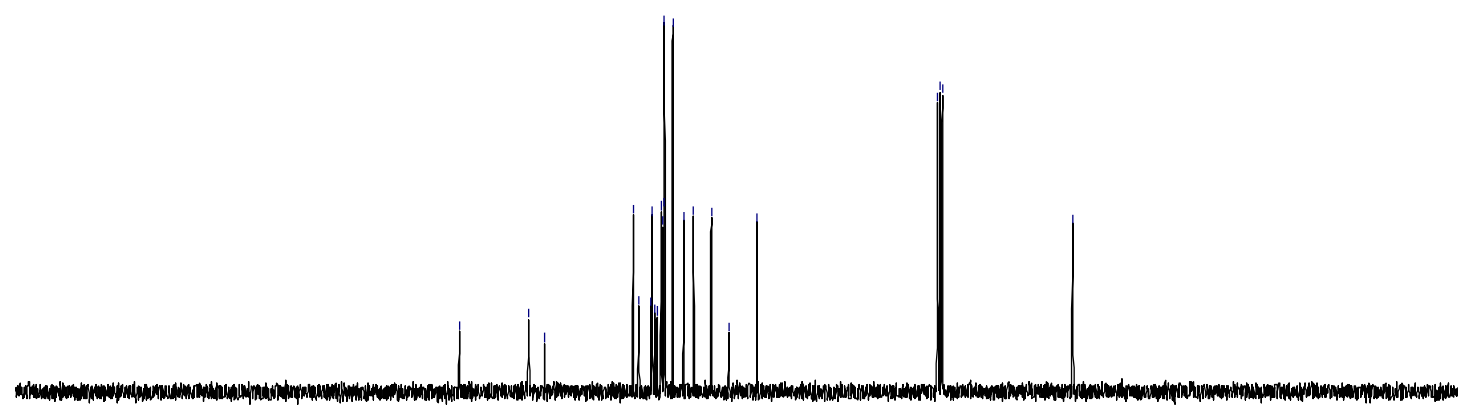

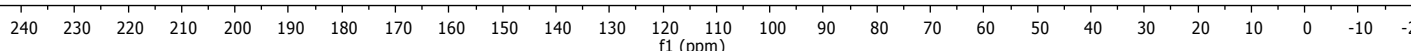




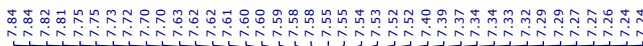

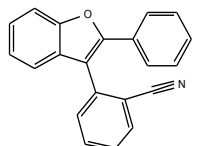

\|\|$\|$
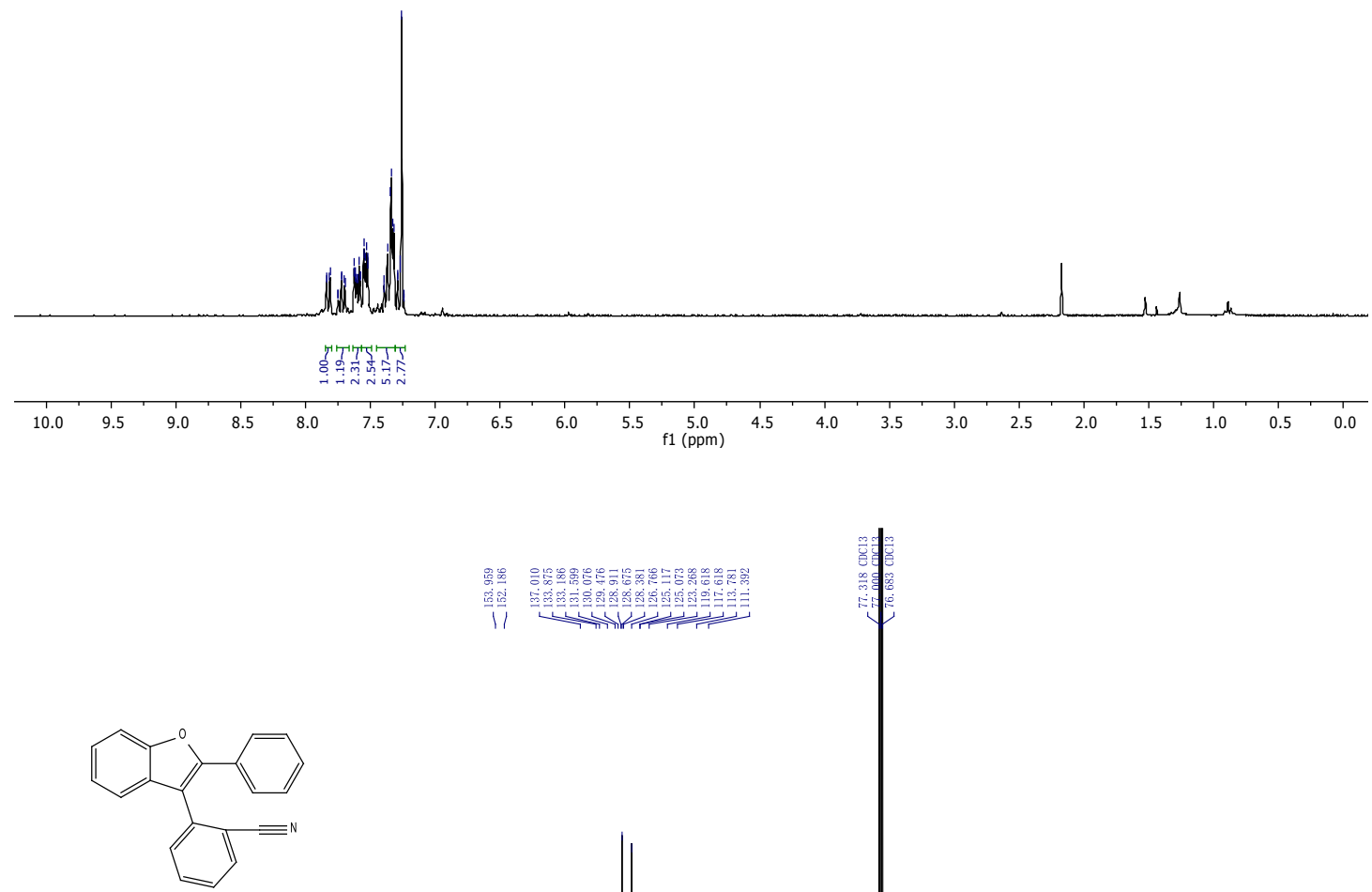

3a

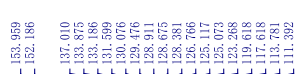

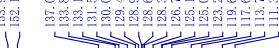
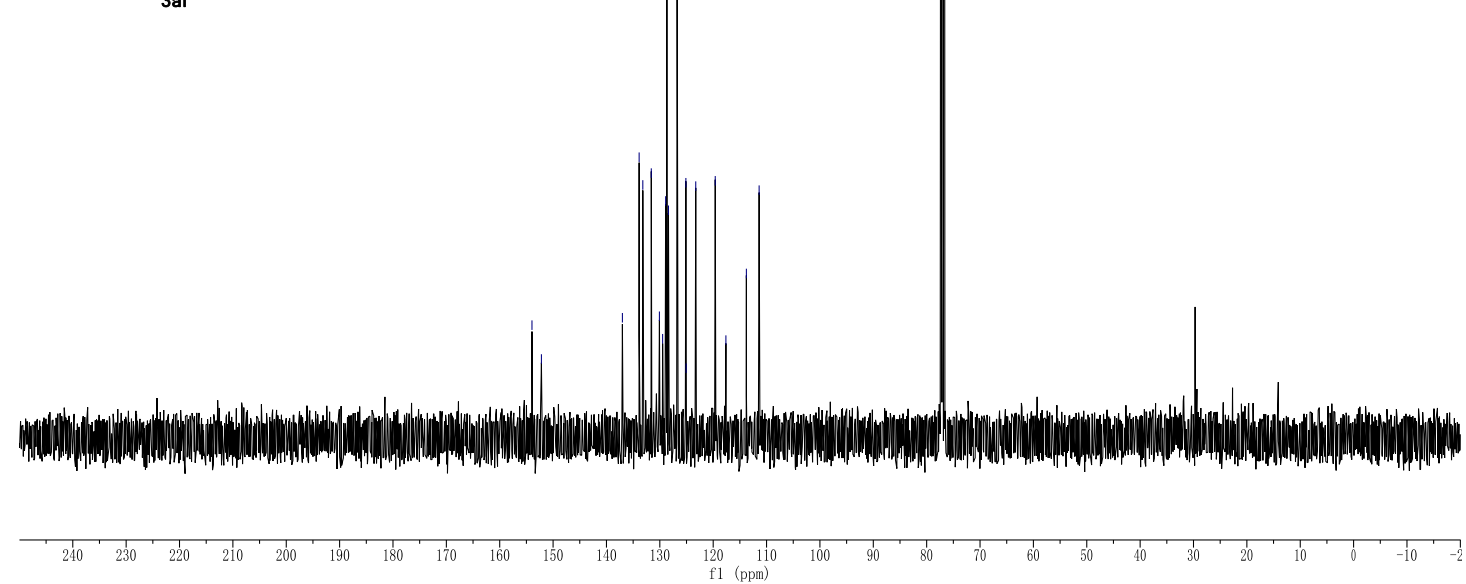


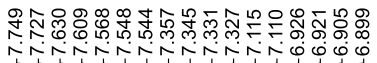

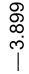

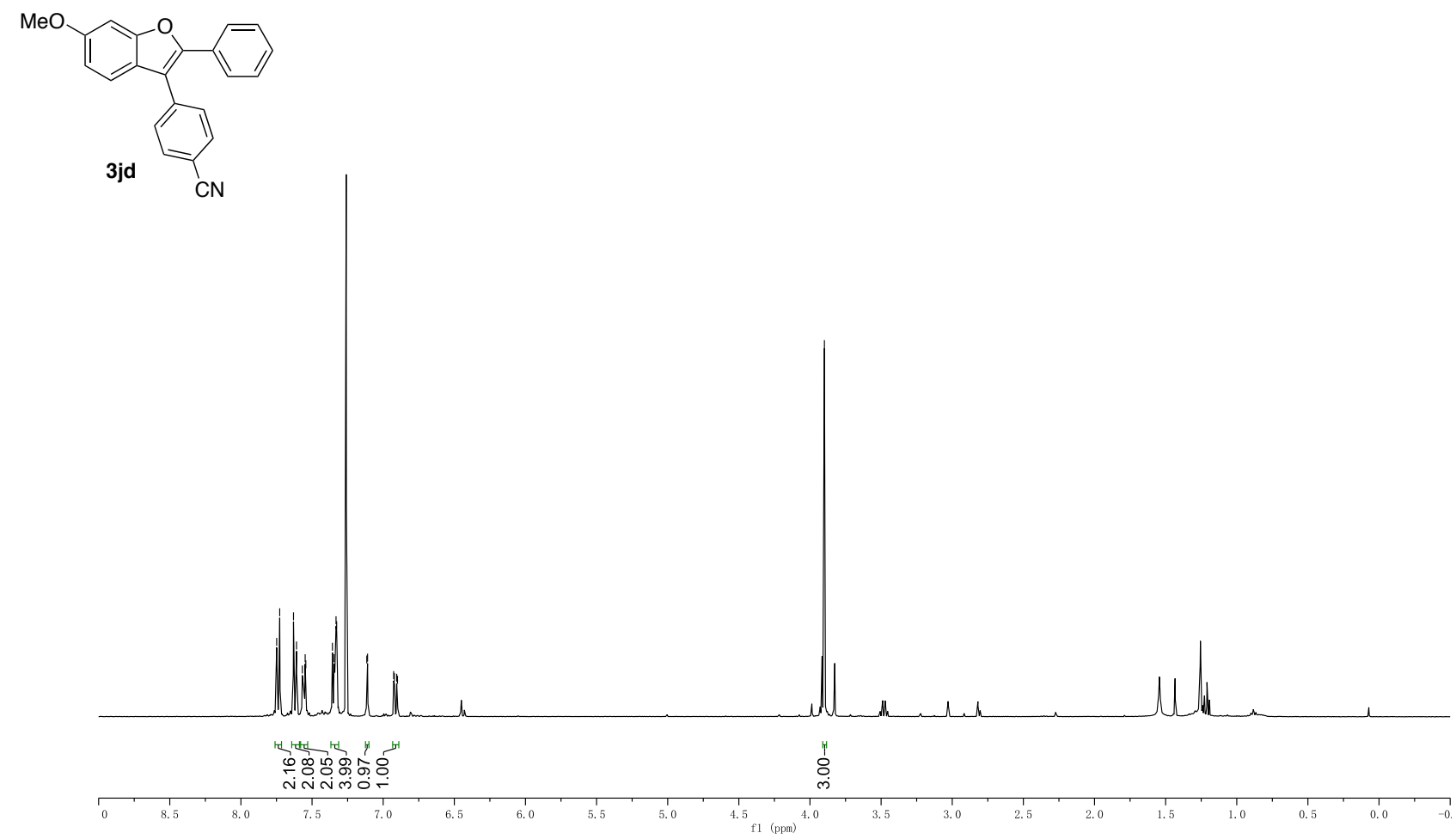

$\mathrm{MeO}$

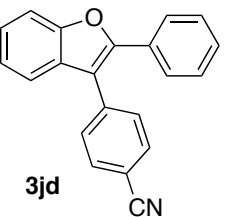

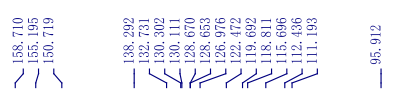

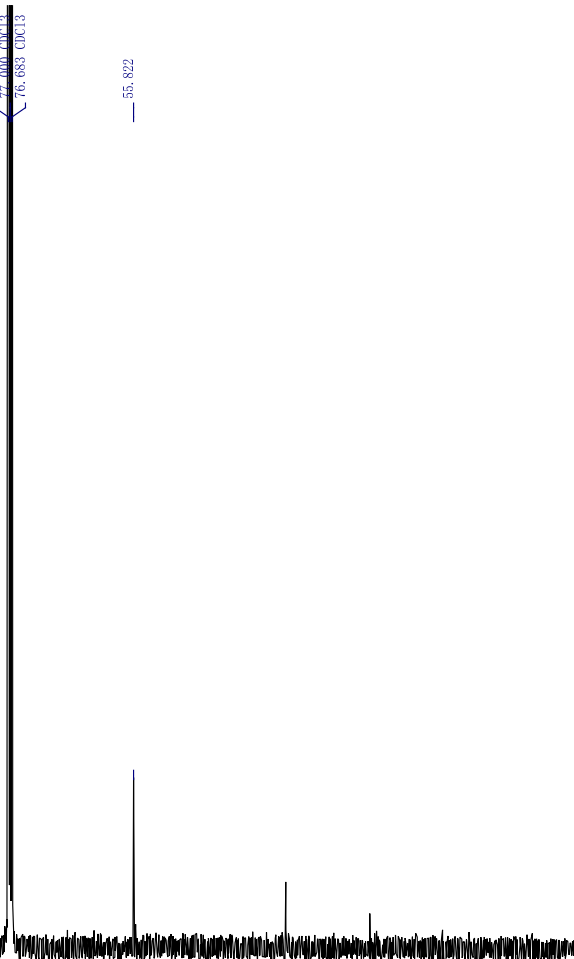

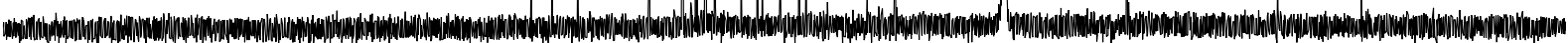

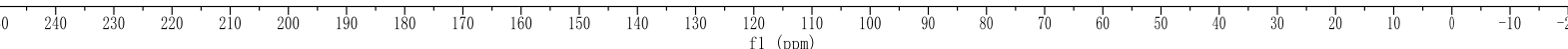



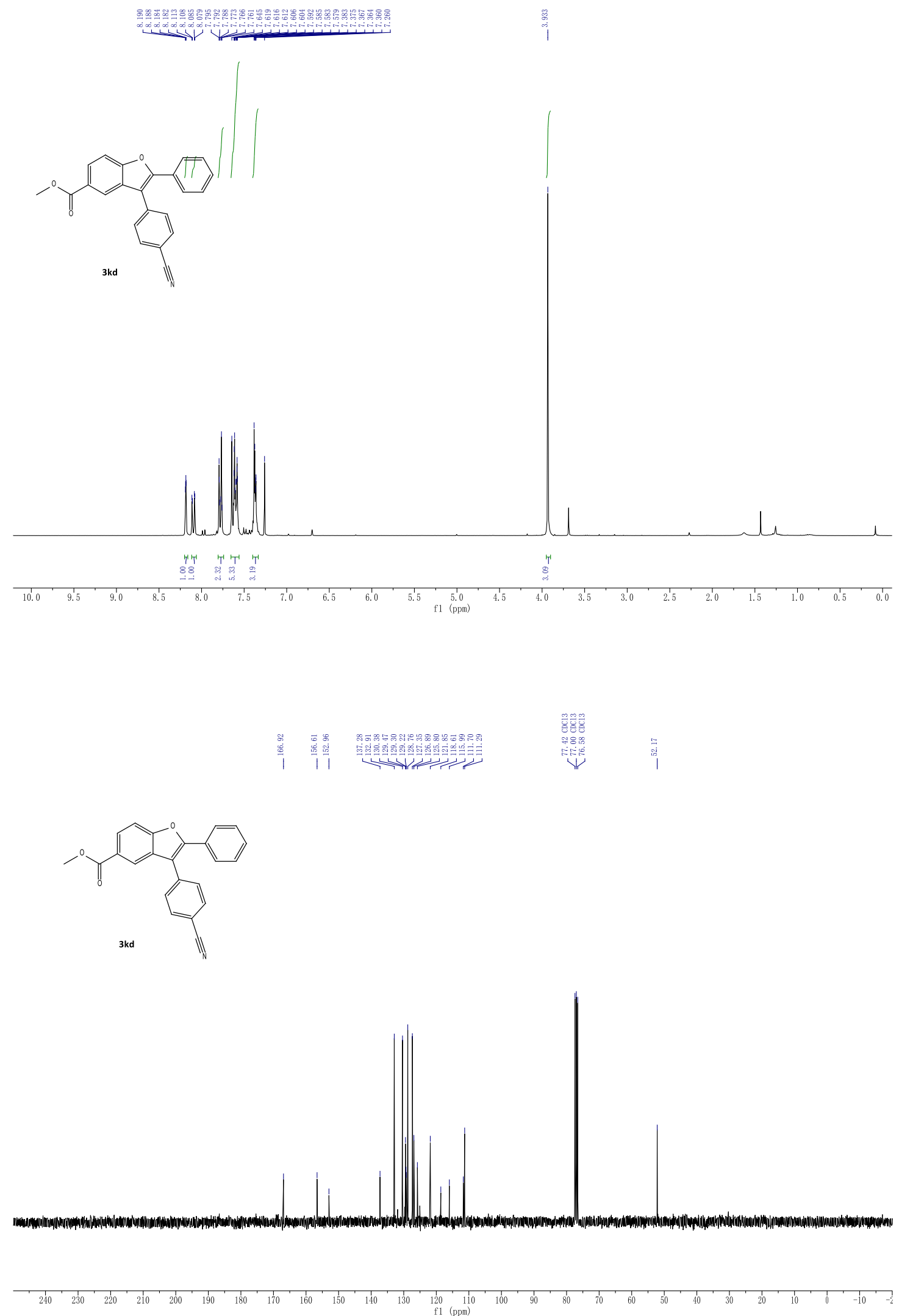

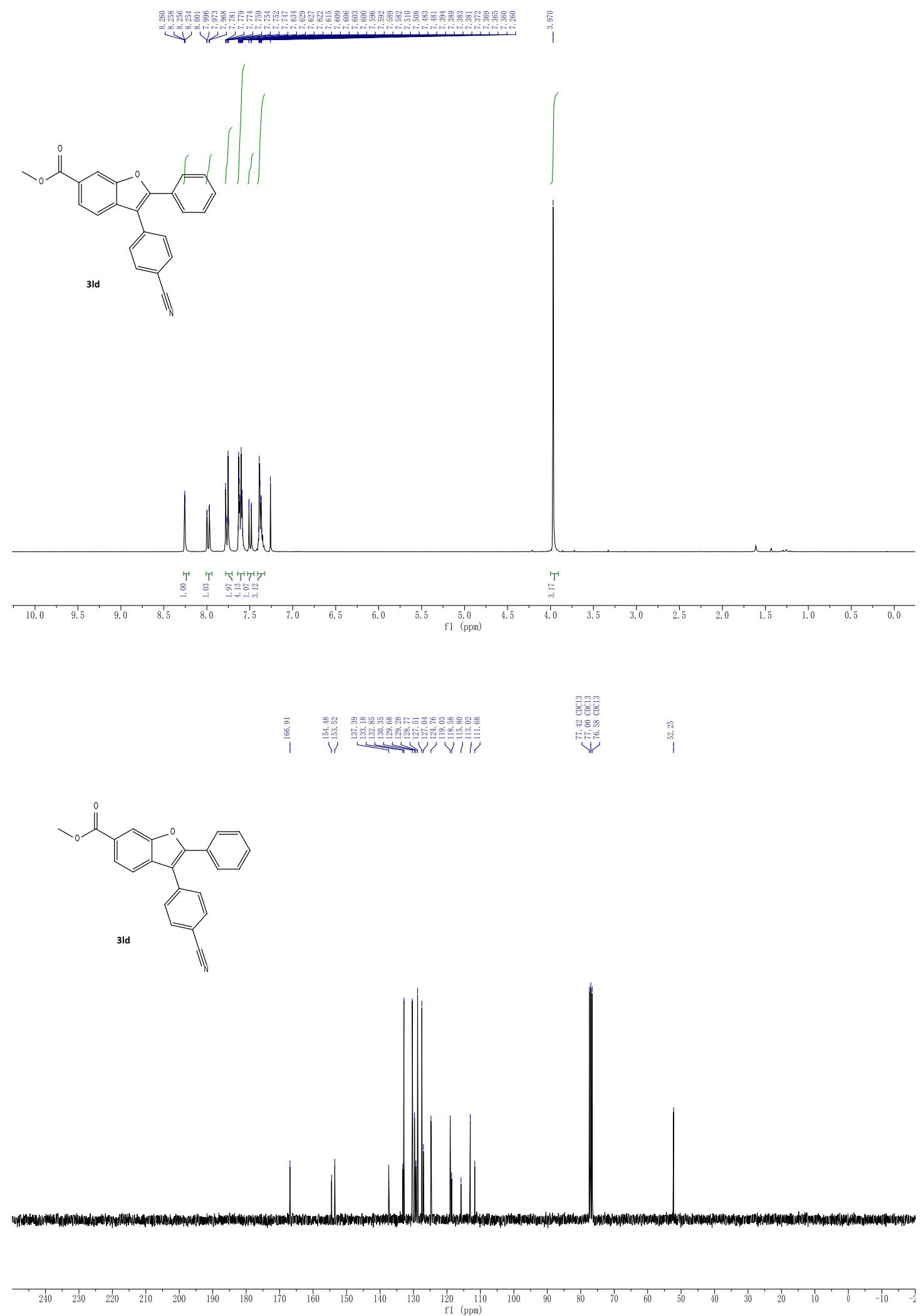


$$
\begin{array}{ll}
- \\
\hline \\
\hline
\end{array}
$$




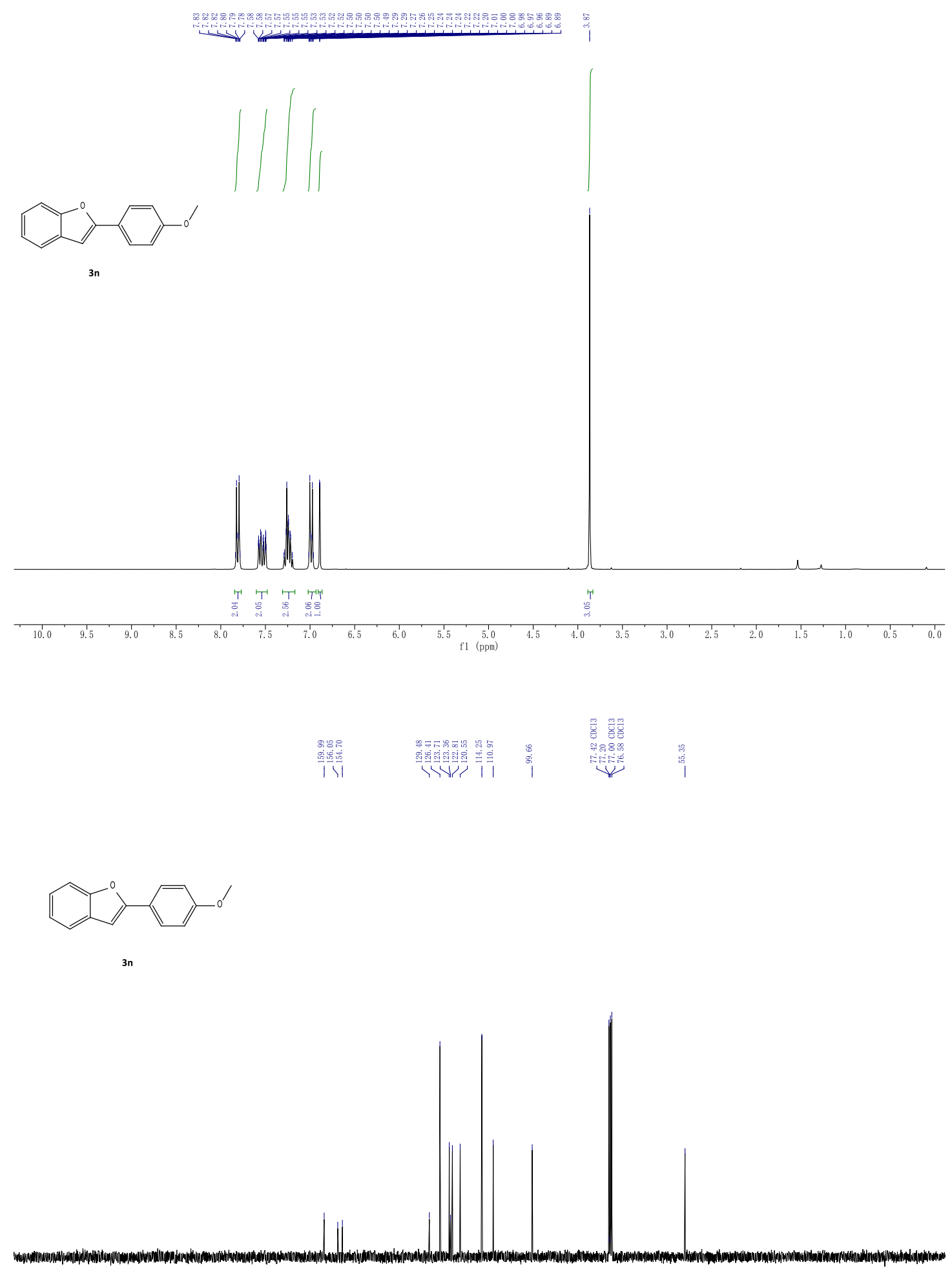

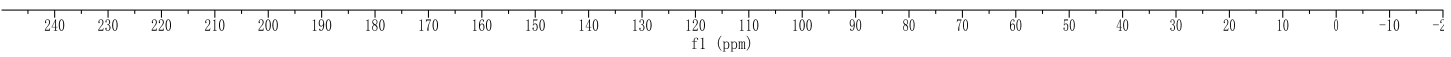




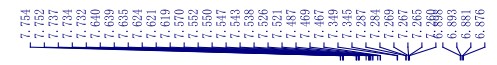
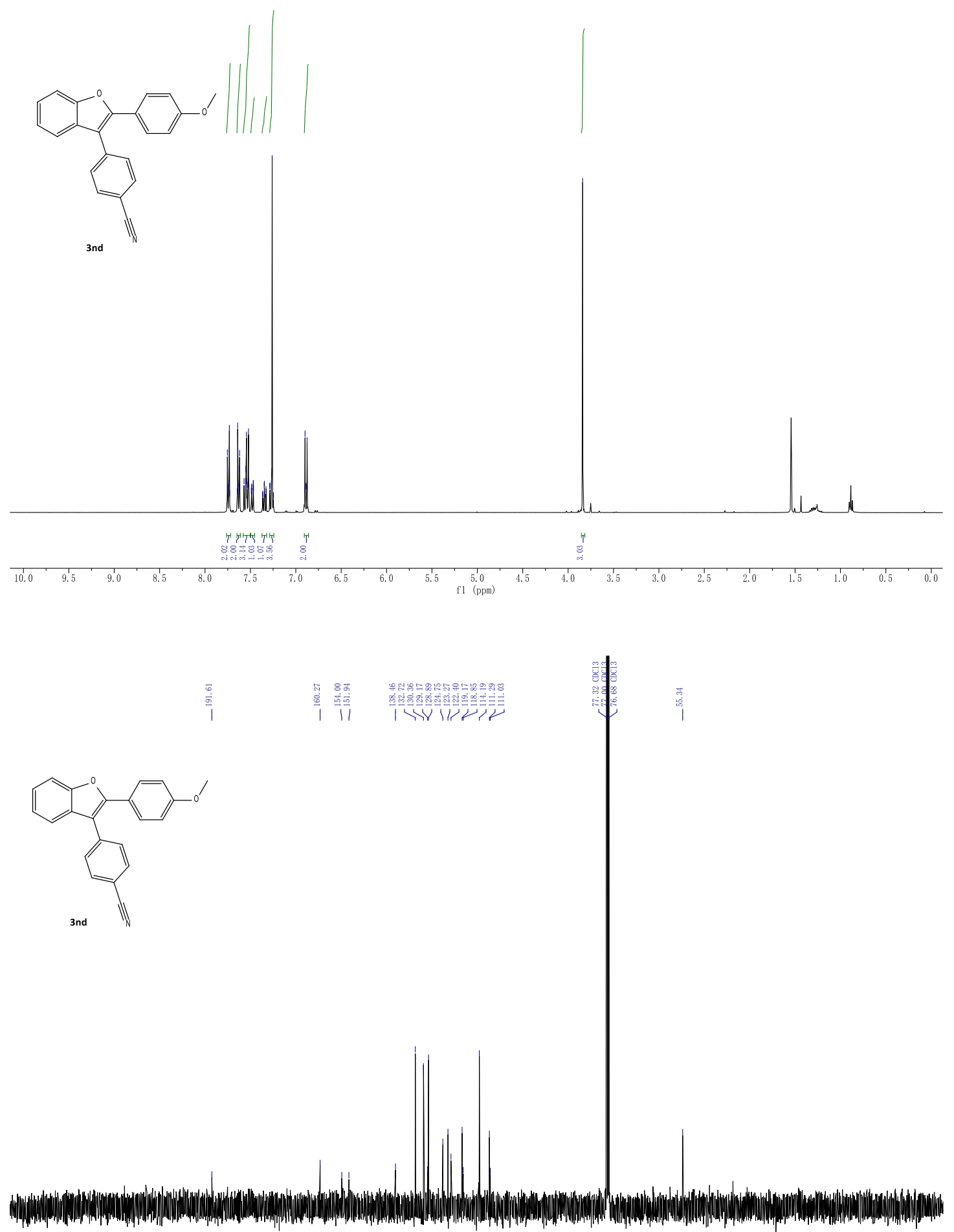

\begin{tabular}{l}
50 \\
\hline 0
\end{tabular}

S24 
兽

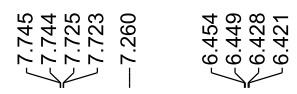

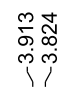

$\underbrace{\mathrm{MeO}}_{0} \mathrm{OMe}$

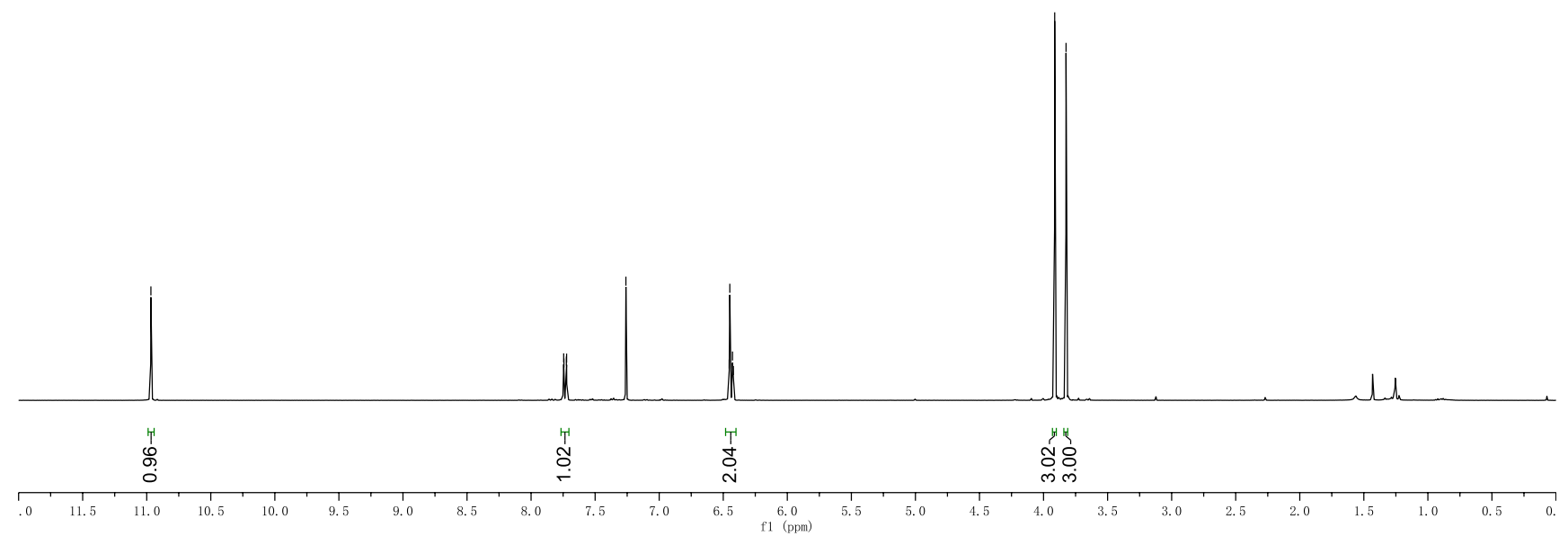

$\mathrm{MeO}$

대요요

옹융

$\underset{\substack{0 \\ \frac{0}{9}}}{i}$

용요

윈으움

萬芒

ใน

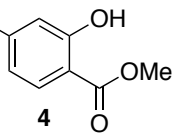

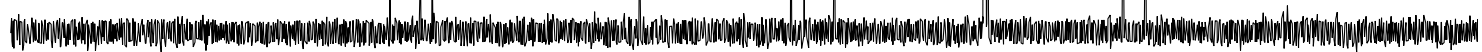

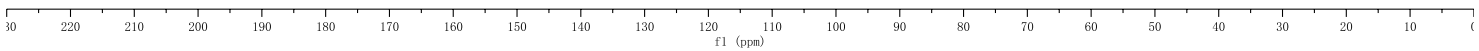



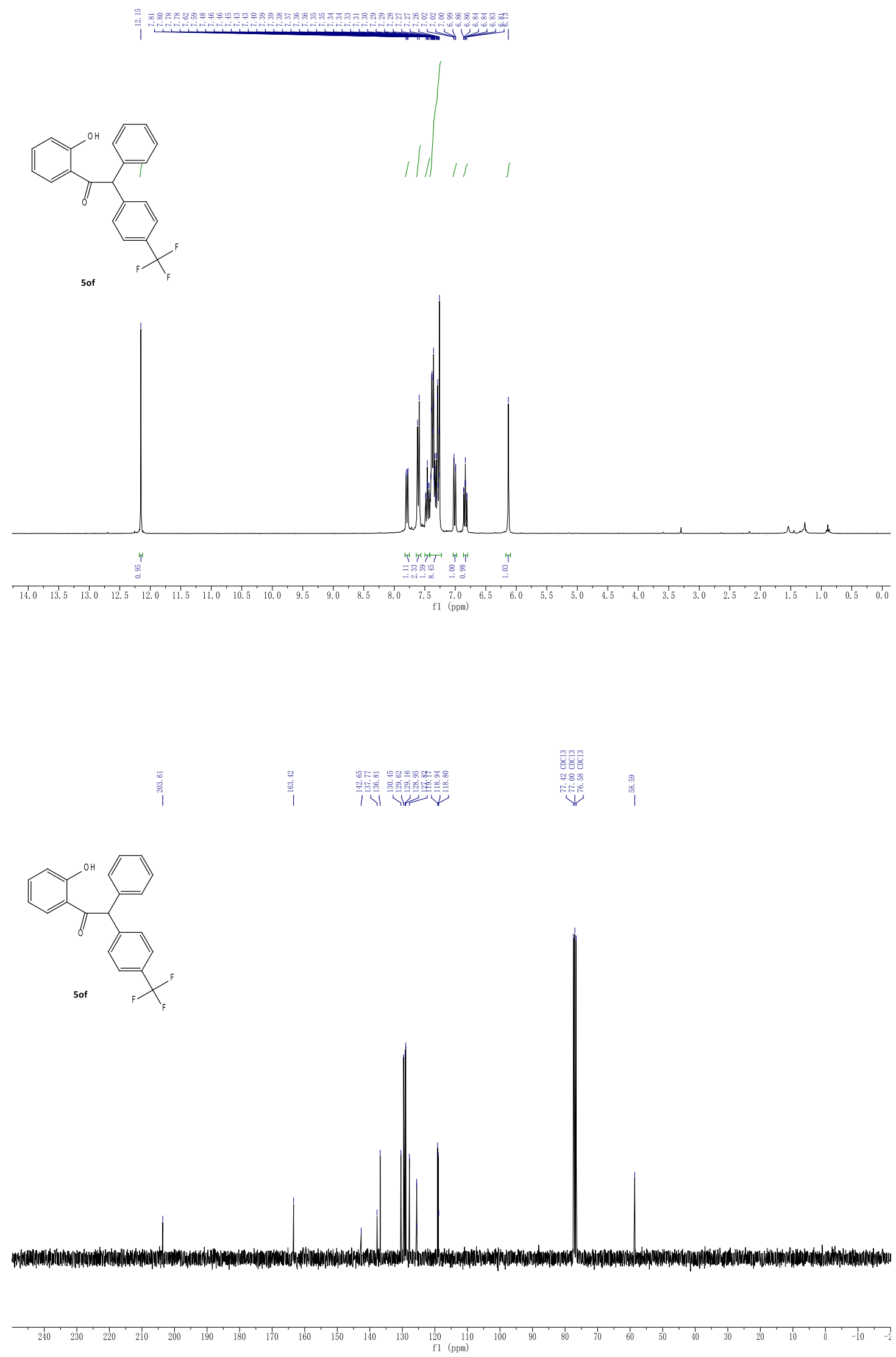


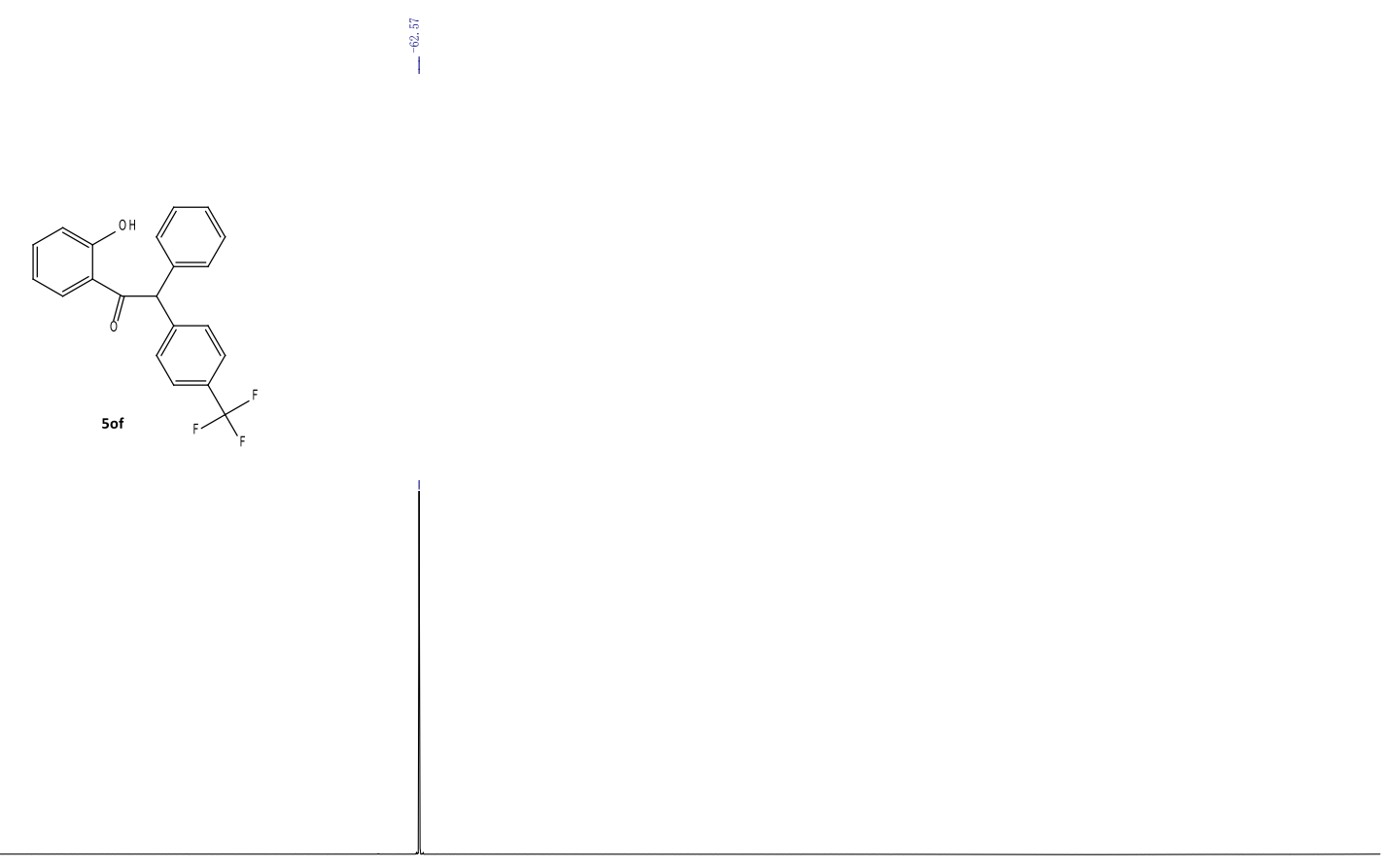

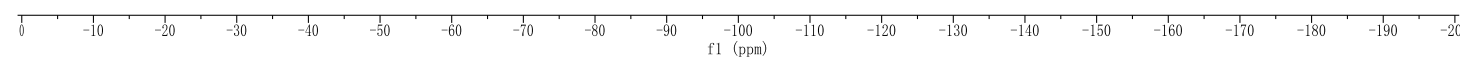




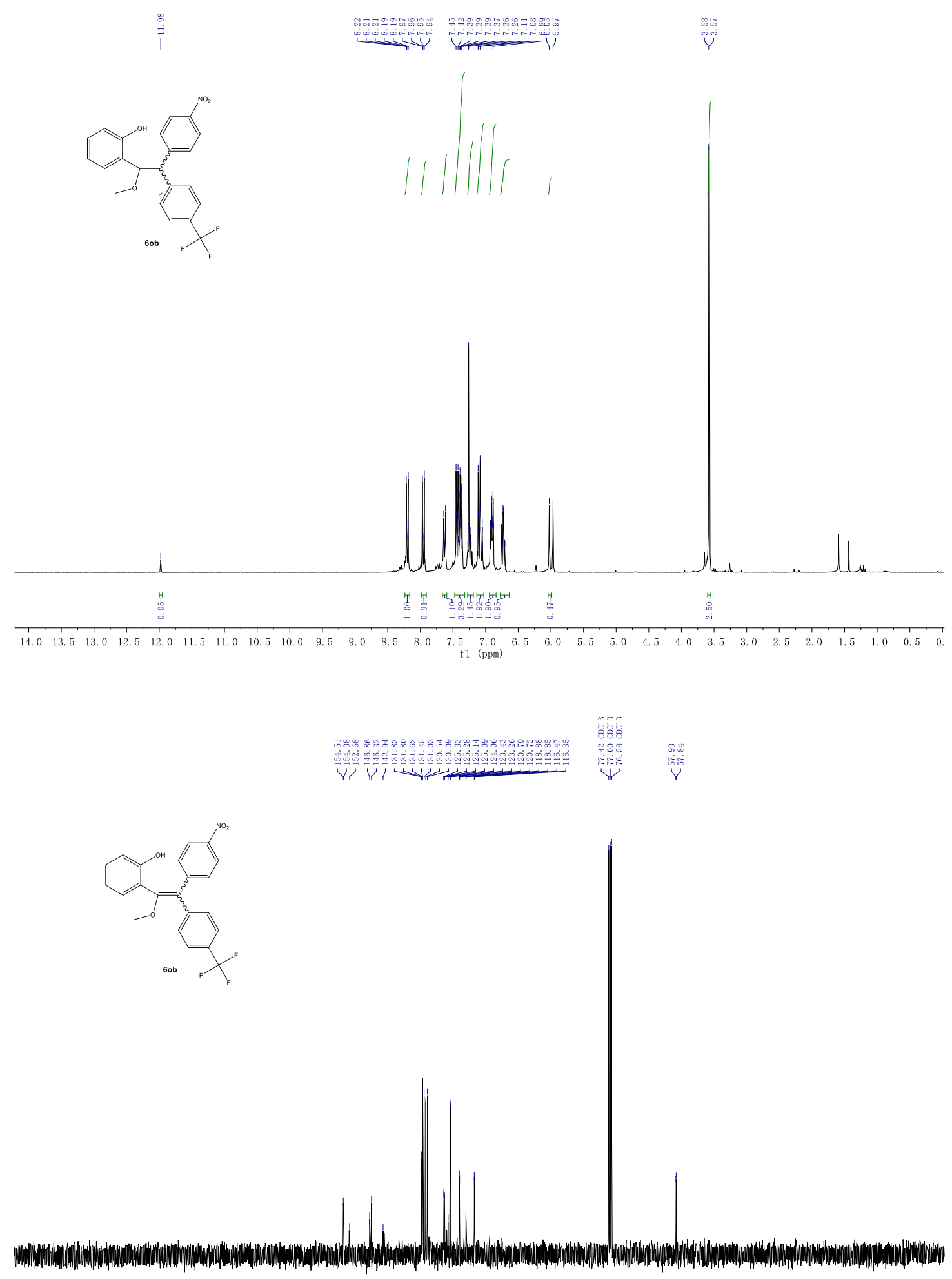

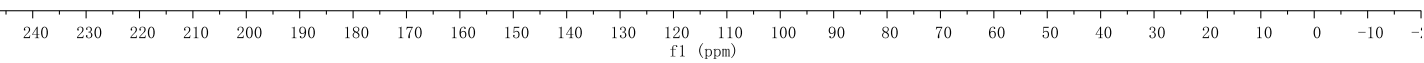




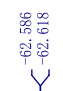

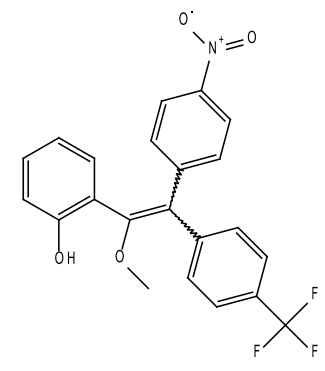

6ob

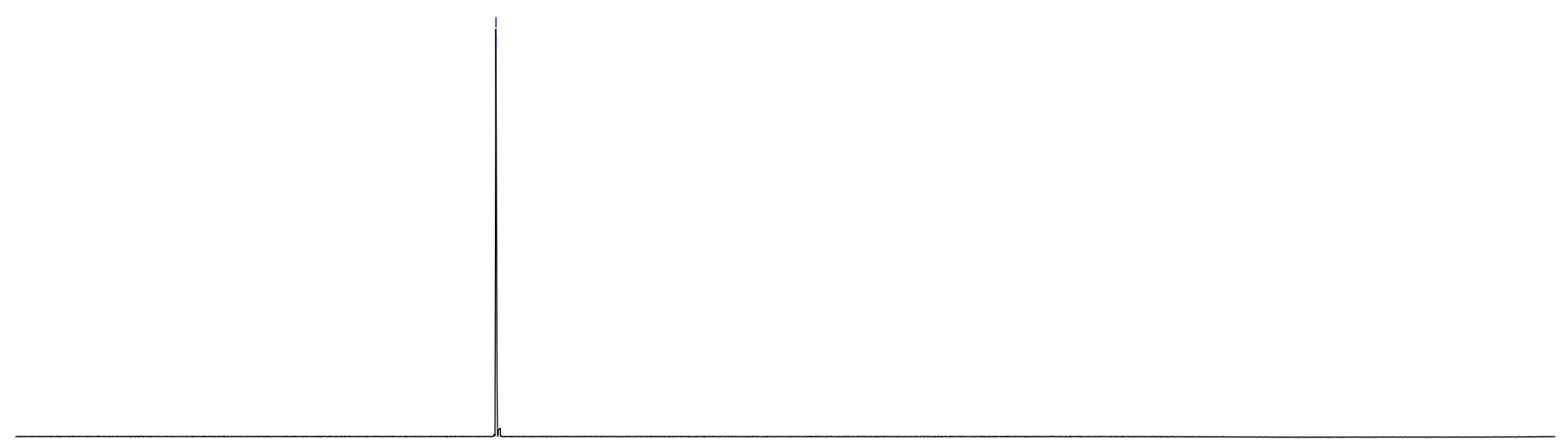

